
60

\title{
Role of the Rapid Gas Desorption of Coal Powders in the Development Stage of
}

\section{Outbursts}

Wei Zhao ${ }^{\text {a,b,c, }}$, Yuanping Cheng ${ }^{\text {a,b,c, }}$, Haina Jiang ${ }^{\text {a,b,c }}$, Kan Jin ${ }^{\text {a,b,c }}$, Haifeng Wang ${ }^{\text {a,b,c }}$, Liang Wang ${ }^{\text {a,b,c }}$

a. Key Laboratory of Coal Methane and Fire Control, Ministry of Education, China University of Mining and Technology, Xuzhou, Jiangsu, 221116, China.

\section{b. National Engineering Research Center for Coal \& Gas Control, China University of Mining} \&Technology, Xuzhou, Jiangsu, 221116, China.

c. School of Safety Engineering, China University of Mining \&Technology, Xuzhou, Jiangsu, 221116,

\section{China.}

d. School of Civil, Mining \& Environmental Engineering, University of Wollongong, NSW, 2522, Australia.

*Corresponding Author

Yuanping Cheng

Tel: +86-516-83885948

Fax: +86-516-83995097

E-mail:381zhao@cumt.edu.cn

Address: National Engineering Research Center for Coal \& Gas Control, China University of Mining \&Technology, Xuzhou, Jiangsu, China.

\begin{abstract}
Based on the desorption experiments of coal particles with different sizes, the possibility of the existence of coal powders in the outburst development stage was studied from the perspective of
\end{abstract}


energy balance and pneumatic conveying. The energy involved in outbursts (gas expansion energy, transport energy and remaining kinetic energy) and the general range of the transport critical particle size (TCPS, the coal particle size with the lowest gas desorption speed causing the outburst coal transport over a certain distance) were calculated. This study concludes that to convey outburst coal, it is necessary to capture the desorbed gas supply because the limited amount of free gas cannot meet the high energy demand. Rapid desorption within a short period is an essential condition for the development of an outburst. Only coal particles with small sizes can exhibit this high desorption speed. Based on the relationship between the initial desorption speed and the particle size, a mathematical model that could be used to estimate the TCPS of the Zhongliangshan outburst (117 $\mu \mathrm{m})$ was established. Historical data regarding the Zhongliangshan outbursts and other mines support the results of calculations and certify the important role that coal powders play in outbursts.

Keyword: outburst energy, gas expansion, extremity particle size, pneumatic conveying, geological structure

\section{Introduction}

Coal and gas outbursts or outbursts are geological failures that occur in underground drainage or mining and consist of the ejection of thousands of coal and rock pieces, as well as considerable amount of gas, into a limited working space within a short period. Different from typical coal extrusions (induced by underground stress) or coal slips (induced by coal weight), outbursts require huge amounts of gas to participate to carry the coal or rock, resulting in a much longer ejection distance. An outburst generally involves the following stages (Farmer and Pooley, 1967; Yu, 1978; Hargraves, 1980; Litwiniszyn, 1985; Paterson, 1986; Lama and Bodziony, 1998; Beamish and Crosdale, 1998; Li et al., 2013; An, 2014; Guo, 2014; Wang et al., 2015): 
I. Preparation stage: The potential outburst energy increases as the coal damage appears which is attributed to the underground stress and gas pressure.

II. Trigger stage: The potential outburst energy exceeds the balance state, leading to a break and an energy release from the coal.

III. Development stage: The damage front sinks deeper into the internal side gradually. Meanwhile, the broken coal outside is consistently transported by a rapid gas flow to the working space.

IV. Termination stage: The ejection ceases, while the gas flow continues for a long period.

Gas pressure and underground stress are generally considered as the main causes of outburst disasters. Hodot (1966) regarded outbursts as the breaking and ejecting processes, indicating that coal is broken by the static and dynamic stress of the ground at first and then a large pressure gradient generated by gas removes the coal to the working space. Jiang (1994) supported this idea by noting that there is an "I"- shaped crack behind the destruction front and at where the gas is stored to form huge energy for transporting the outburst coal (Xu et al., 2006). Guan et al. (2009) indicated that an outburst is driven by the gas pressure and took it as an explosive eruption. During the crushing process, although gas pressure and underground stress behave cooperatively, it is commonly accepted that the gas pressure can be neglected because of the large difference in their contributions to an outburst (typically, the underground stress is several times larger than the gas pressure). Hence, underground stress is recognized as the primary contributor in the outburst preparation stage. During the ejection process (the development stage), outburst coal is separated from the steady wall, indicating that no force from the ground engages in this transport process. Indeed, in this case, gas is the main factor affecting the process. 
However, a small volume of gas cannot generate this large transport energy. Outbursts need a large volume of gas to be generated instantaneously to produce a high pressure gradient, pushing the crushed coal into the mining space. Without a rapid gas emission rate, the pressure will not grow fast and the mass transport of coal will be impossible. In the investigations of outbursts, specialists usually consider the gas exhausted during the period beginning from the moment of concentration rising to the time when the gas has decreased to the normal level as the final gas emission amount. This period typically lasts several to dozens of days, whereas the effective outburst dynamic process only lasts around few tens of seconds (Lama and Bodziony, 1998). Therefore, gas emission statistics primarily pertain to low-concentration gases released from nearby cracks or outburst coal itself after an outburst ends. Figure 1 shows the roadway gas concentration variations of three recent outbursts that occurred in 2013 and 2014; the effective gas (gas required to carry the coal), where lies in the rapid increasing zone of gas concentration, constitutes only a small proportion of the total investigated amount. Gas concentrations can reach or even exceed the limit of the monitor immediately after an outburst begins, forming a gas flow with concentrations dozens or hundreds of times higher than the normal.

\section{[FIGURE 1]}

Obviously, gas can appear via one of two pathways: either gas is thrown from coal or it is not. The area around an outburst hole, which contains rather integrated and unbroken coal, continues to release copious amounts of gas but at a much slower rate compared with the crushed coal. Thus, the primary contributor to the transport of coal is the gas from the outburst coal itself. When exploring the category of gas, i.e., either free or adsorbed gas, researchers concluded that no adsorbed gas contributes to outbursts because no adequately fast speed is observed during the initial seconds 
following an outburst for the integrated or big size coal lump (Sobczyk, 2011; Wen et al., 2002). In contrast, the regions easy to produce outbursts, which often features ample fractures, faults and folds, are usually of heavily broken or small size coal particles. The Table 1 and Figure 2 provide statistics pertaining to 31 outbursts that occurred in China. Among them, 25 outbursts, which account for nearly $81 \%$ of the total outbursts, occurred in the special structural regions, with rapid desorption and poor strength. Besides, after an outburst ends, there was a certain percentage of coal particles with a radius less than $100 \mu \mathrm{m}$, whose desorption goes much faster (Hu, 2007).

\section{[TABLE 1]}

\section{[FIGURE 2]}

High desorption speed benefits the instant storage of gas in outburst fractures, making the pressure threshold easy to reach (Hodot, 1966; Williams and Weissmann, 1995; Wang et al., 2015). Therefore, it is important to clarify the true contribution of these two types of gas to outbursts and to discuss the possibility of coal powders existing in outbursts theoretically. Trough comparison between transport energy and gas expansion energy obtained from the free or adsorbed gas, we can determine whether it requires the adsorbed gas to supply the free gas to transport outburst coal. If the desorption cannot be neglected, we will clarify how this desorption is produced, how fast desorption the transport needs, and how small the particle size is. These efforts will greatly contribute to further clarifying the mechanism of outbursts and allow for better predictions of these phenomena.

\section{[FIGURE 3]}

\section{Theory}

\subsection{Outburst energy}

Because of the complexity and variability of outbursts, it is more possible to analyze this 
phenomenon from an energy perspective. Significant researches conducted by Hodot (1966), Gray (1980), Valliappan and Zhang (1999), Jiang and Yu (1996), Wen et al. (2002), Cai and Xiong (2005), Li et al.(2012) and Tan (2013) has provided a detailed analysis of outburst energy. It is generally concluded that the gas expansion energy in addition to the elastic energy of coal is transferred to the coal crushing energy, the transport energy and the remaining kinetic energy of gas after carrying the coal, as shown in the following equation:

$$
W_{1}+W_{2}=W_{3}+W_{4}+W_{5}
$$

where $W_{1}$ is the gas expansion energy, $W_{2}$ is the elastic energy of coal, $W_{3}$ is the coal crushing energy, $W_{4}$ is the coal-gas transport energy, and $W_{5}$ is the remaining kinetic energy of the gas.

Zheng (2004) calculated the elastic energy of coal and the expansion energy of gas for several outburst accidents, which indicates that the elastic energy only accounts for a few thousandths of the total outburst energy. Thus, in the outburst development stage, the elastic energy of coal can be ignored and the transport energy of coal is completely from the gas, as follows:

$$
W_{1}=W_{4}+W_{5}
$$

\subsubsection{Gas expansion energy}

Gas expansion occurring over a short period can be simplified to an adiabatic process, which satisfies the following equation:

$$
P_{1} V_{1}^{n}=P_{0} V_{0}^{n}(n>1)
$$

where $P_{1}$ and $P_{0}$ represent the gas pressure and atmospheric pressure, respectively; $V_{1}$ and $V_{0}$ are the gas volumes under pressures $P_{1}$ and $P_{0}$, respectively; $n$ is the adiabatic coefficient. For gas mixtures primarily composed of methane, $n$ is usually chosen to be 1.3 (Wen et al., 2002).

The gas expansion energy can be expressed as follows: 


$$
W_{1}=\frac{P_{0} V_{0}}{n-1}\left[\left(\frac{P_{1}}{P_{0}}\right)^{\frac{n-1}{n}}-1\right]
$$

Because gas adopts a free state and an adsorbed state, Equation 4 can b4 factored into the components shown in Equation 5.

$$
W_{1}=\frac{P_{0}}{n-1}\left(V_{0}^{a}+V_{0}^{f}\right)\left[\left(\frac{P_{1}}{P_{0}}\right)^{\frac{n-1}{n}}-1\right]=w_{a}+w_{f}
$$

where $V_{0}{ }^{\mathrm{a}}$ and $V_{0}^{\mathrm{f}}$ represent the volume of the adsorbed gas and the free gas under pressure $P_{0}$, respectively; $w_{\mathrm{a}}$ and $w_{\mathrm{f}}$ represent the energy contributions of the adsorbed gas and the free gas, respectively.

It is easy to obtain data regarding the initial gas pressure $P_{1}$ and the initial free gas volume $V_{1}^{\mathrm{f}}$ in an outburst investigation, whereas the contributive gas volume $V_{0}$ is difficult to determine. Therefore, Equation 5 must be modified into a more practical form, as follows:

$$
W_{1}=\frac{P_{0} V_{0}}{n-1}\left[\left(\frac{P_{1}}{P_{0}}\right)^{\frac{n-1}{n}}-1\right]=\frac{P_{0}}{n-1}\left(V_{1}^{a}+V_{1}^{f}\right)\left(\frac{P_{1}}{P_{0}}\right)^{\frac{1}{n}}\left[\left(\frac{P_{1}}{P_{0}}\right)^{\frac{n-1}{n}}-1\right]=w_{a}+w_{f}
$$

where $V_{1}{ }^{\mathrm{a}}$ and $V_{1}^{\mathrm{f}}$ represent the volume of the adsorbed gas and the free gas under $P_{1}$, respectively.

\subsubsection{Transport energy of coal}

The transport energy calculation varies with the final shape of the coal dump. When only horizontal displacements exist, the transport energy can be expressed as shown in Equation 7 (Hodot, 1966):

$$
W_{4}=\operatorname{Sm}[g(f \cos \alpha \mp \sin \alpha)]
$$

where $S$ represents the distance over which the coal is ejected, $m$ is the coal mass, $f$ is the friction coefficient, $g$ is the gravity acceleration, and $\alpha$ is the coal seam angle. 
When $\alpha=0$, Equation 7 can be simplified into the form shown in Equation 8:

$$
W_{4}=f S m g
$$

Coal-gas transport is a complex process, and it is difficult to find an accurate formula that incorporates all of the factors, such as the coal collision loss and heat loss. Thus, the result of Equation 8 will be smaller than the actual value. However, if these results still require adsorbed gas to provide energy, then a participative role of the adsorbed gas will be required.

\subsubsection{Remaining kinetic energy of gas}

Ideally, the coal-gas transport process on a straight roadway can be treated as a homogeneous powder flow occurring in a pipe. Previous studies have shown a strong relationship between the gas-solid flow rate and the corresponding flow state. Generally, following a decrease in the flow rate, the states of suspension flow, stratified flow, sedimentation flow, plug flow and, finally, blockage will occur sequentially (Kurnia et al., 2014; Lin, 2004; Molerus, 1996; Pan, 1999). Normally, there exists a critical blockage velocity that characterizes the flow state from the blockage to the plug flow. When the speed decreases below this critical speed, the gas will not have sufficient power to support the transport of coal, and coal will begin to form a deposit. The gas desorbed after this moment will be of no use to outbursts. Therefore, the remaining kinetic energy of the gas, which is termed ineffective gas, can be calculated with the critical blockage velocity.

Regarding the critical blockage velocity of coal powders in pipes, Xiong et al. (2009) set up a formula that is proper on a small scale, which provides a good fitting to the laboratory data. Cong (2012, 2013) supposed that Xiong's formula generates a large error on an industrial scale and established a more reasonable transport equation in his doctoral dissertation:

$$
v_{r}=\frac{G}{A \rho_{b}}
$$


where $v_{\mathrm{r}}$ is the critical blockage velocity, $G$ is the mass of coal per second, $A$ is the cross-section area, and $\rho_{\mathrm{b}}$ is the natural bulk density.

Hence, the remaining kinetic energy of gas $W_{5}$ can be calculated with Equation 10:

$$
W_{s}=\frac{1}{2} m v_{r}^{2}=\frac{1}{2} m\left(\frac{G}{A \rho_{b}}\right)^{2}=\frac{1}{2} V_{0} \rho_{0}\left(\frac{G}{A \rho_{b}}\right)^{2}
$$

where $m$ is the outburst coal mass and $\rho_{0}$ is the gas density under pressure $P_{0}$, which is typically

\section{$0.1 \mathrm{MPa}$.}

By introducing all of the aforementioned factors into Equation 2, we can obtain the final energy conversion during the transport shown in Equation 11:

$$
\frac{P_{0}}{n-1}\left(V_{1}^{a}+V_{1}^{f}\right)\left(\frac{P_{1}}{P_{0}}\right)^{\frac{1}{n}}\left[\left(\frac{P_{1}}{P_{0}}\right)^{\frac{n-1}{n}}-1\right]=f S m g+\frac{1}{2} V_{0} \rho_{0}\left(\frac{G}{A \rho_{b}}\right)^{2}
$$

\subsection{Source of rapid desorbed gas}

\subsubsection{Desorption speed demand for conveying outburst coal}

The free gas of outburst coal can be obtained from Equation 12:

$$
V_{1}^{f}=\varepsilon V_{c}=\varepsilon m / \rho_{c}^{a}
$$

where $V_{\mathrm{c}}$ represents the volumes of coal, $\varepsilon$ is porosity of coal, and $\rho_{c}^{a}$ donates the apparent density of coal.

Using the Equations 3 and 12 to get the total gas volume involved in the outburst $V_{0}$ and the free gas volume $V_{0}^{\mathrm{f}}$, under pressure $P_{0}$, we can then deduce the adsorbed gas engaging in outbursts $\left(V_{0}^{\mathrm{a}}\right)$ :

$$
V_{0}^{a}=V_{0}-V_{0}^{f}=V_{0}-V_{1}^{f}\left(\frac{P_{1}}{P_{0}}\right)^{\frac{1}{n}}=V_{0}-\frac{\varepsilon m}{\rho_{c}^{a}}\left(\frac{P_{1}}{P_{0}}\right)^{\frac{1}{n}}
$$

If $V_{0}^{a} \geq 0$, then the adsorbed gas is necessary; if $V_{0}^{a}<0$, then the free gas is the only contributor to the coal conveying. 
When adsorbed gas exists, the desorption of adsorbed gas is required. The desorption speed is the desorbed volume per gram per second $(\mathrm{mL} / \mathrm{g} \cdot \mathrm{s})$. Assuming that the outburst lasts for $t_{\mathrm{o}}$ seconds, we can easily obtain the desorption speed required to convey the outburst coal using Equation 14:

$$
v_{a}=\frac{V_{0}^{a}}{m t_{o}}=\frac{V_{0}}{m t_{o}}-\frac{\varepsilon m}{\rho_{c}{ }^{a} m t_{o}}\left(\frac{P_{1}}{P_{0}}\right)^{\frac{1}{n}}
$$

where $v_{\mathrm{a}}$ represents the desorption speed demand for conveying the outburst coal.

\subsubsection{Estimation of the TCPS during the conveying process}

Desorption of gas form coal depends on the gas content, gas pressure, temperature and moisture et al.. When all the external conditions stay the same, the only factor affecting the desorption for the same coal is the particle size. Concerning the relationship between desorption speed and coal particle size, researchers have preferred to analyze the variation through laboratory tests and have assumed the role that the rapid desorption plays in outbursts. In this laboratory-field way, it is difficult to estimate the required gas desorption speed and the proper particle size range required for a real outburst. Efforts to clarify the true speed and particle size, conversely in a field-laboratory way, are essential and valuable.

The unipore diffusion model can be expressed as shown in Equation 15 (Busch and Gensterblum, 2011; Crank, 1975; Ruckenstein et al., 1971; Smith and Williams, 1984; Crosdale et al., 1998; Li et al., 2014; Ni et al., 2014):

$$
\frac{Q_{t}}{Q_{\infty}}=1-\frac{6}{\pi^{2}} \sum_{n=1}^{\infty} \frac{1}{n^{2}} e^{-D n^{2} \pi^{2} t r^{2}}
$$

where $D$ is the diffusion coefficient, $t$ is the diffusion time, $r$ represents the coal particle radius, and $Q_{t}$ and $Q_{\infty}$ are the total desorption volume per gram at time $t$ and the final desorption volume per gram, respectively. 
For short times, Equation 15 can be simplified as Equation 16:

$$
\frac{Q_{t}}{Q_{\infty}}=\frac{6}{\sqrt{\pi}}\left(\frac{D}{r^{2}} t\right)^{\frac{1}{2}}
$$

Assume that the $D$ values are independent of $t$; we take the derivative of the expression with respect to $t$, and a formula describing the relationship between the coal particle radius and the desorption speed is obtained:

$$
v_{t}=\frac{d Q_{t}}{d t}==\frac{6 Q_{\infty}}{r} \sqrt{\frac{D}{\pi}}(\sqrt{t})^{\prime}=\frac{6 Q_{\infty}}{r} \sqrt{\frac{D}{\pi}} \cdot \frac{1}{2}(t)^{-\frac{1}{2}}=\frac{3 Q_{\infty}}{r} \sqrt{\frac{D}{\pi t}}
$$

The average desorption speed can be deduced from Equation 18:

$$
\overline{v_{t}}=\frac{Q_{t}}{t}=\frac{6 Q_{\infty}}{r} \sqrt{\frac{D}{\pi t}}
$$

Hence, for short outbursts, at any time, the average desorption speed can be expressed as follows:

$$
\overline{v_{t}}=\frac{1}{r} f\left[D(r), Q_{\infty}(r)\right]
$$

Regarding the adsorption capacity $\left(Q_{\infty}\right)$, a common consensus is that a decrease in particle size can hardly damage the micropore system of coal, which dominates the adsorption capacity or the Langmuir volume $V_{\mathrm{L}}$. Thus, $Q_{\infty}$ will not change very much with particle size. Guo et al. (2014) tested the isothermal adsorption of coal with different particle sizes and obtained several coincident Langmuir curves. The same result was obtained in studies by Ruppel et al. (1974), Liu (2011), Zhang et al. (2009), Zhang et al. (2005), Li et al. (2013). It is generally acknowledged that crushing occurs easily on the weak side of coal, which consists of large numbers of macropores and mesopores. This damage only increases the external area exposed to the air and makes little contribution to the internal pore area. In addition, the smallest crush particle size in an outburst is assumed to be approximately $10 \mu \mathrm{m}$, whereas the upper limit of the micropore's diameter is on the nanoscale (Hodot, 1966). This difference in diameters also makes a change in adsorption capacity impossible. 
Additionally, with an assumption that coal is an isotropic material, the diffusion coefficient $D$ will not vary with the particle size under the same concentration difference. Ideally, the parameters of $Q_{\infty}$ and $D$ can be treated as stable values that are not affected by the particle size. Therefore, the average desorption speed and particle size conform to a proportional relationship (Equation 20).

$$
\frac{v_{1}}{v_{2}}=\frac{d_{2}}{d_{1}}
$$

where $v_{1}$ and $v_{2}$ represent the desorption speed of gas from coal particles with the corresponding diameter, $d_{1}$ and $d_{2}$.

The diameter is six times the ratio of the volume and surface area (Equation 21). Suppose that the crushed coal particles are densely packed. Hence, the total coal volume will not change during crushing, and the decrease in particle size only leads to an increase in the number of coal particles as well as the surface area. Breaking shortens the diffusion distance and increases the exposure area so that the desorption speed increases.

$$
S^{\prime}=a \cdot \Delta S=\frac{V_{\text {toall }}}{\Delta V} \cdot \Delta S=\frac{V_{\text {total }}}{4 / 3 \pi r^{3}} \cdot 4 \pi r^{2}=\frac{3 V_{\text {total }}}{r}=\frac{6 V_{\text {total }}}{d}
$$

where $S^{\prime}$ is the new surface area of particles after crushing; $a$ is the number of particles of a radius of $r$ after crushing; $\Delta S, \Delta V$ is the surface area and volume for a single particle after crushing, respectively; $V_{\text {total }}$ is the total volume of coal.

In fact, the inhomogeneity of coal affects the accuracy of Equation 20. Watanabe (1985), Yang (1987) believed that there should be a correction factor $\theta(0<\theta<1)$ in this proportional relationship, as shown in Equation 22.

$$
\frac{v_{1}}{v_{2}}=\left(\frac{d_{2}}{d_{1}}\right)^{\theta}
$$

Based on this equation, the TCPS can be estimated from the measured desorption speed for a 
certain particle size.

\section{Experiments and results}

The desorption experiments were conducted with the typical volumetric method (Diamond and Schatzel, 1998). Because it is impossible to obtain the original coal sample from the Zhongliangshan coalmine (the outburst occurred too long ago and is not repeatable), the coal sample of the Machang outburst accident is taken as a replacement for further desorption tests. Both are coking coals and originated from the Longtan Formation in Southwest of China. Around these two outburst sites, faults and folds are easily to be seen. The average gas content of these two coalseams is also close, about $18.3 \mathrm{~m}^{3} / \mathrm{t}$ (Zhongliangshan) and $16.4 \mathrm{~m}^{3} / \mathrm{t}$ (Machang), respectively. First, the coal sample collected from the outburst site was sieved into seven particle size ranges, which were $0.01 \sim 0.08 \mathrm{~mm}$, 0.08 0.2 $\mathrm{mm}, 0.2 \sim 0.25 \mathrm{~mm}, 0.25 \sim 0.5 \mathrm{~mm}, 0.5 \sim 1 \mathrm{~mm}, 1 \sim 3 \mathrm{~mm}$ and $3 \sim 4 \mathrm{~mm}$. Then about $50 \mathrm{~g}$ of coal sample for each size range was placed into a container with $60{ }^{\circ} \mathrm{C}$ water and the vacuum pump began to exhaust the gas existing in the coal. When the pumping was over, the container was injected with methane quickly and kept in a $30^{\circ} \mathrm{C}$ water bath for adsorption equilibrium. After this process, the valve 2 was opened and the container was then connected to the gas volume measuring cylinder. The desorption volume at different time was recorded and a figure describing the relationship between the gas desorption volume and time was constructed at last. The test equipment is shown in Figure 4.

\section{[FIGURE 4]}

Figure 5 and Figure 6 depict the desorption volume variation over time for the first 10 minutes and describe the relationship between the average desorption speed in the first minute and the average particle size, respectively. It is easy to conclude that the rate of gas desorption decreases with 
the particle size, showing a logarithmic variation. There is an extremity particle size dividing the whole desorption stage, the rapid desorption stage and the normal or slow desorption stage. This result is consistent with the observations of other related studies (Busch et al., 2004; Watanabe, 1985; Yang, 1987; Banerjee, 1988; Cao and Qiu, 2007; Zhang et al., 2009; Liu, 2011). Zhou (1990) thought that the extremity particle size $D_{\mathrm{e}}$ range is approximately $0.5 \sim 10 \mathrm{~mm}$, essentially on the millimeter level. The existence of the extremity particle size is determined by the pore-fracture system of coal. Because the flow difficulty in the fracture system is much smaller than that in the pore system when stress is not applied. The initial damage to the fracture zone improves the permeability of fractures but has little influence on the permeability of matrix. Thus the whole transport of gas through the porous system is not changed markedly. When the particle size decreases to a certain value, below the matrix size, the seepage system disappears, a great number of closed pores will be opened and become exposed to air. Busch et al.(2004) believed that larger particles possess more complex pore structures which can be partly damaged during crushing. Nandi and Walker (1975) concluded that crushing produces additional macropores, leading to a positive influence on the desorption speed. Guo (2014) used the mercury intrusion method to test the pore distribution variation with six different particle sizes. He found with decreasing grain size, the pore volume and average pore size of the matrix increase, and the diffusion coefficient of macropores as well as that of micropores holds a similar increasing law when the desorption data are fitted by the bidisperse diffusion model. It is believed that crushing shortens the diffusion distance and enlarges the exposure pore areas, and gas is much easier to enter the interparticle voids, making the desorption speed increase dramatically.

Based on Figure 6, it can be deduced that the extremity particle size of the test sample is approximately $1 \mathrm{~mm}$ and the correction factor $\theta$ is 0.62 . When the particle size is smaller than $1 \mathrm{~mm}$, 
the rate of desorption increases sharply with their sizes' decline.

[FIGURE 5]

[FIGURE 6]

\section{Outburst energy and TCPS calculation for a real case}

\subsection{Overview of the Zhongliangshan outburst}

The Zhongliangshan outburst, a test that commenced on November $4^{\text {th }}$ of 1977 , is the sole field simulation with relatively detailed outburst data that exists in China (Hu and Wen, 2013). After this test and upon consideration of the high risk to coalmine workers, the Chinese government introduced rigorous controls to prevent outburst accidents, and underground field tests were prohibited. In the Zhongliangshan outburst, the outburst coal mass was $817 \mathrm{t}$, and the abnormal gas volume was 38540 $\mathrm{m}^{3}$ (including the volume of gas after the outburst, which did not contribute to the outburst). The outburst lasted for 39 seconds. Two pressure inspection holes (\#1 and \#2), one flow inspection hole (\#3) and one temperature inspection hole (\#4) were established. The variation of these parameters is shown in Figure 7.

From Figure 7, it can easily be seen that 1.5 2 seconds after the outburst commenced, the pressure in hole \#2 ( $2 \mathrm{~m}$ from the outburst front ) began to decrease, and when the time advanced to the sixth second, a similar decrease was witnessed in hole \#1 (14 m from the outburst front ). The pressure hysteresis indicates that the outburst gas release initially occurred at the outburst front and then proceeded to the a further point only a few seconds after the coal was crushed, and finally the flow became a gas-solid transport powered by a static head of 0.3 0.6 MPa. This phenomenon supported the theory that coal is crushed by great stress and then is discharged by an enormous amount of gas. 
[FIGURE 7]

\subsection{Energy and gas demand for the Zhongliangshan outburst}

Several parameters based on observational data are collected in Table 2 .

\section{[TABLE 2]}

First, we modify the Equations 6 and 10 into simpler forms, shown in Equations 23 and 24:

$$
\begin{gathered}
W_{1}=\frac{P_{0} V_{0}}{n-1}\left[\left(\frac{P_{1}}{P_{0}}\right)^{\frac{n-1}{n}}-1\right]=\lambda_{1} V_{0} \\
W_{5}=\frac{1}{2} V_{0} \rho_{0}\left(\frac{G}{A \rho_{b}}\right)^{2}=\lambda_{2} V_{0}
\end{gathered}
$$

where $\lambda_{1}$ and $\lambda_{2}$ can be regarded as the gas expansion energy factor and the remaining kinetic energy factor, respectively.

With the data above, the expansion energy of free gas, the transport energy of coal, and the remaining kinetic energy of the gas can be calculated, as shown in Table 3.

\section{[TABLE 3]}

It is clear that $\lambda_{1}$ is much greater than $\lambda_{2}$, indicating that the remaining kinetic energy of the gas can be ignored during the carrying process and that all the gas expansion energy is converted into the transport energy of coal. In addition, approximately $5.61 \times 10^{8} \mathrm{~J}$ of desorption gas expansion energy, or $1799 \mathrm{~m}^{3}\left(30^{\circ} \mathrm{C}, 0.1 \mathrm{MPa}\right)$ of adsorbed gas, will be required for this transport, which is nearly 6.3 times greater than the energy of free gas (Figure 8). However, because of the age and irreproducibility of the data, an exact description of the Zhongliangshan outburst is difficult to obtain. Certain parameters and conditions need to be established empirically to obtain a reliable answer. Although inaccurate, the results provide strong evidence that a certain percentage of adsorbed gas is involved in outbursts and typically plays a crucial role. 
[FIGURE 8]

\subsection{Gas desorption speed of coal with a normal particle size and the TCPS estimation}

For a fracture-pore porous media, it is widely accepted that the diffusion dominates the flow in pores and the permeability controls that in fractures. Although Zhou (1990) provided a general description of the extremity particle size range, more researchers preferred a size of $3 \mathrm{~mm}$ as the dividing line between the fracture system and pore system, and they often adopt $1 \sim 3 \mathrm{~mm}$ as their particle size choice (Yang, 1987; An et al., 2011; Liu, 2013; Zhao et al., 2014; Li et al., 2014; Guo, 2014), after the finding that desorption speed of gas from coal particles mostly begins to increase at the size of approximately $3 \mathrm{~mm}$ (Yang, 1987). It is believed that diffusion dominates the gas flow in coal particles with particle sizes less than $3 \mathrm{~mm}$, which can be assumed to be the matrix size.

Therefore, the fracture-pore system can be simplified into a unipore system with a particle size less than $3 \mathrm{~mm}$, and the diffusion model can be implied directly. Various studies on the desorption volume and pressure were conducted to establish an outburst risk evaluation index, from which we can gain a simple relationship between the first minute desorption volume and the initial pressure (Gao and Wang, 2011; Toraño et al., $2012 \mathrm{Li}$ et al., 2011):

$$
Q_{1}=B P^{C}
$$

where $Q_{1}$ represents the desorption volume at the first minute, $P$ is the initial equilibrium pressure, and $B$ and $C$ are two fitting parameters.

Table 4 presents the desorption data obtained in our laboratory with a normal particle size from eight sections over the past few years. These desorption tests were conducted with the same method mentioned above, although with different initial equilibrium pressures. Nevertheless, the relationship between $Q_{1}$ and $P$ can always be determined. Based on that relationship, we can easily obtain the 
desorption speed of various types of coal under a pressure of 1.75 MPa. Based on information gathered in the table, it is observed that the desorption speeds of particles of normal sizes are within the range of $10^{-3}$ to $10^{-2} \mathrm{~mL} / \mathrm{g} \cdot \mathrm{s}$. With respect to the coal rank, there is a hook-shaped variation. The desorption speed decreases gradually to a certain point; it then increases with the coal rank (Figure 9). Medium-rank coal exhibits the smallest desorption speed among the different types of coal.

\section{[TABLE 4]}

\section{[FIGURE 9]}

For the Zhongliangshan outburst, the supply of desorption gas is $1799 \mathrm{~m}^{3}\left(0.1 \mathrm{MPa}, 30^{\circ} \mathrm{C}\right)$, based on Equation 14, we can obtain the average desorption speed required for conveying the $817 \mathrm{t}$ coal mass in $39 \mathrm{~s}, 0.05646 \mathrm{~mL} / \mathrm{g} \cdot \mathrm{s}$, which is much larger than normal desorption speed of $10^{-3}$ to $10^{-2}$ $\mathrm{mL} / \mathrm{g}$. s. This big difference indicates that contributions from bigger size particles are very small and coal needs to be crushed. Considering that the $0.5 \sim 1 \mathrm{~mm}$ rate of desorption of gas from Machang coal is $0.01782 \mathrm{~mL} / \mathrm{g} \cdot \mathrm{s}$ (Figure 6) and the correction factor $\theta$ is 0.62 , we can expect the TCPS in the Zhongliangshan outburst to be $117 \mu \mathrm{m}$ using Equation 22.

If we take all the statistics regarding the normal rate of desorption in Table 4, without consideration of the effect of the extremity particle size and the coal rank, and assume the factor $\theta$ still be 0.62 , then this particle size range is $20 \sim 640 \mu \mathrm{m}$ (Equation 22). Because the results are average values, a certain fraction of coal with a particle size less than the calculated TCPS exists, which would benefit the energy accumulation and contribute to a higher possibility of outbursts.

\section{Verification of the existence of coal powders}

Studies on the increasing number of accidents in China have proven the widespread existence of coal powders in outbursts (Lama and Bodziony, 1998; Hodot, 1966). These pervasive coal powders 
prove the role of the rapid desorption in outbursts, not just for the Zhongliangshan outburst itself. These powders share some common characteristics.

(1) At the edge of a coal dump, with a slope angle smaller than the natural-rest angle, there are a large number of coal powders. These powders can be easily blown away by a gentle wind. When there is water nearby, a thin layer of coal powders will float on the water surface. Figure 10 shows the coal powders that existed during the Machang outburst.

\section{[FIGURE 10]}

(2) Good sorting of coal was found during outbursts. Figure 11 gives a sketch map of the coal powder distribution along the roadway of the Daping outburst. From this graph, we can see that, for the same site along the roadway and along the same cross profile, the particle size decreases with the height. Horizontally, the shorter the distance from the outburst hole is, the greater the size of the coal particles is.

\section{[FIGURE 11]}

(3) Extreme uniformity exists in the particle size distribution. $\mathrm{Hu}$ (2007) conducted an exploration on the coal particle composition in the four times' outbursts occurred in the Zhongliangshan coalmine in the 1970s and 1980s. The weight distribution of the different particle size ranges of the four coal samples is shown in Table 5. It can be easily concluded that all the coal samples contained a large fraction of small size coal powders $(d<1 \mathrm{~mm})$, accounting for $54.1 \%$, $34.2 \%, 33.9 \%$ and $34.1 \%$ of the total collection, respectively. For the sizes that are less than $100 \mu \mathrm{m}$, this fraction decreased to $25.4 \%, 4.3 \%, 3.5 \%$ and $6.6 \%$. Coal lump $(d>10 \mathrm{~mm})$ also contributed fractions of $20.0 \%, 27.2 \%, 16.2 \%$ and $30.8 \%$ for each accident. The entire particle size distribution was a non-Gaussian distribution with a variation greater than ten orders of magnitude. Hu used the 
Rosin-Rammler model to fit the data and found that the uniformity coefficient was much less than 1 , which indicated the extreme uniformity of the outburst coal size distribution.

\section{[TABLE 5]}

The average particle size of these samples is difficult to estimate. However, a certain proportion of coal with a particle size of approximately $100 \mu \mathrm{m}$ truly exists, and the entire order of magnitude is similar to that indicated by the former calculation. Restricted to the objective conditions, we make several assumptions and simplifications to obtain a reasonable answer. The crash energy loss, heat loss and coal crushing time, as well as the final coal dump shape, are generally neglected or strictly simplified. It is unavoidable that there are some errors, but we must admit the existence of coal powders with millimeter and micrometer sizes.

\section{Conclusions}

(1) Outburst coal transport requires the participation of a large amount of desorption gas. Only expansion energy from free gas cannot achieve the transport of the coal mass of such large amount. For the Zhongliangshan outburst, approximately $5.61 \times 10^{8} \mathrm{~J}$ of desorption gas expansion energy from the adsorbed gas, will be required for transporting coal, which is nearly 6.3 times greater than the energy from the free gas.

(2) Desorption speed of gas should reach certain value to produce a high pressure gradient instantaneously in outbursts. For the Zhongliangshan outburst, the average desorption speed for transporting $817 \mathrm{t}$ coal mass in $39 \mathrm{~s}$ is about $0.05646 \mathrm{~mL} / \mathrm{g} \cdot \mathrm{s}$.

(3) Rapid desorption is generated by coal particles of small sizes. Coal with particle sizes of millimeter and micrometer is required in outbursts. For the Zhongliangshan outburst, coal lumps need to be crushed to powders of less than $117 \mu \mathrm{m}$ to obtain such a large amount of outburst energy. 
(4) Considering the important role that coal powders play in outbursts, the entire outburst process can be summarized as: In the preparation and trigger stages, high stress breaks the coal, and the coal surface area increases dramatically. When the particle size decreases to the extremity particle size, desorption begins to increase exponentially. Gas expansion energy accumulates quickly until reaching the outburst energy threshold. During the stage of outburst development stage, high-speed gas blows the broken coal away. The energy then begins to release, and for a certain period, a coal dump with a smaller angle than the natural-rest angle is established (Figure 12).

[FIGURE 12]

\section{Acknowledgments}

This research was supported by the National Science Foundation of China (No. 51374204 and 51474212), the China Postdoctoral Science Foundation (No. 2014T70561), Visitor Foundation of State Key Laboratory of Coal Mine Disaster Dynamics and Control (Chongqing University) (No. 2011DA105287-FW201405), and A Project Funded by the Priority Academic Program Development of Jiangsu Higher Education Institutions (PAPD). We would like to express our appreciation to acknowledge Yan Liu, Weipeng Niu and other members in our research team for the help provided in experiments and language editing. Comments by all anonymous reviewers are also appreciated.

\section{References}

An, F.H., Cheng, Y.P., Wu, D.M. and Li, W., 2011. Determination of coal gas pressure based on characteristics of gas desorption. Journal of Mining \& Safety Engineering 28(1), 81-85.

An, F.H., Cheng, Y.P., Wang, L. and Li, W., 2013. A numerical model for outburst including the effect of adsorbed gas on coal deformation and mechanical properties. Computers and Geotechnics 54, 222-231.

An, F.H., 2014. Preparation and initiation of coal and gas outburst and its numberical modelling study. China University of Mining \& Technology, China, Xuzhou. 147 pp.

Banerjee, B.D., 1988. Spacing of fissuring network and rate of desorption of methane from coals. Fuel 67(11), 1584-1586.

Beamish, B.B. and Crosdale, P.J., 1998. Instantaneous outbursts in underground coal mines: An 
overview and association with coal type. International Journal of Coal Geology 35(1), 27 - 55.

Busch, A., Gensterblum, Y., Krooss, B.M. and Littke, R., 2004. Methane and carbon dioxide adsorption-diffusion experiments on coal: upscaling and modeling. International Journal of Coal Geology 60(2), 151-168.

Busch, A. and Gensterblum, Y., 2011. CBM and $\mathrm{CO}_{2}-\mathrm{ECBM}$ related sorption processes in coal: a review. International Journal of Coal Geology 87(2), 49-71.

Cai, C.G. and Xiong, Y.X., 2005. Theoretical and experimental study on crushing energy of outburst-proneness coal. Journal of China Coal Society 30(1), 63-66.

Cao, K.L. and Qiu, H.S., 2007. Gas desorption law of clastic coal core. China Mining Magazine 12, 119-123.

Cong, X.L. et al., 2012. Investigations of pulverized coal pneumatic conveying using $\mathrm{CO}_{2}$ and air. Powder Technology 219, 135-142.

Cong, X.L., 2013. Study on relationship between flow patterns and pipeline pressure signals in dense-phase pneumatic conveying of pulverized coal. East China University of Science and Technology, China, Shanghai. 147 pp.

Crank, J., 1975. The Mathematics of Diffusion. Oxford University Press, pp. 89-91.

Crosdale, P.J., Beamish, B.B. and Valix, M., 1998. Coalbed methane sorption related to coal composition. International Journal of Coal Geology 35, 147-158.

Diamond, W.P. and Schatzel, S.J., 1998. Measuring the gas content of coal: A review. International Journal of Coal Geology 35(1-4), 311-331.

Farmer, I.W. and Pooley, F.D., 1967. A hypothesis to explain the occurrence of outbursts in coal, based on a study of West Wales outburst coal, International Journal of Rock Mechanics and Mining Sciences \& Geomechanics Abstracts. Elsevier, pp. 189-193.

Gao, J.L. and Wang, Y., 2011. Research on the relationship between the drilling cutting gas desorption index $\Delta \mathrm{h}_{2}$ and parameters of gas occurrence. Applied Mechanics and Materials 99, 1312-1318.

Gray, I., 1980. The mechanism of, and energy release associated with outbursts, Symposium on The Occurrence, Prediction and Control of Outbursts in Coal Mines, AusIMM, Southern Queensland Branch.

Guan, P., Wang, H. and Zhang, Y., 2009. Mechanism of instantaneous coal outbursts. Geology 37(10), 915-918.

Guo, J.Q., Kang, T.H., Kang, J.T., Zhao, G.F. and Huang, Z.M., 2014. Effect of the lump size on methane desorption from anthracite. Journal of Natural Gas Science and Engineering 20, 337-346.

Guo, P.K., 2014. Research on laminar spallation mechanism of coal and gas outburst propagation, china university of mining \& technology, China, Xuzhou. 167 pp.

Hargraves, A.J., 1980. A review of instantaneous outburst data. Proc. The Occurrence, Prediction and Control of Outbursts in Coal Mines. The Aust. Inst. Min. Metall., Melbourne, 1-18.

Hodot, B.B., 1966. Outburst of coal and coalbed gas (Chinese Translation). China Coal Industry Press, Beijing: 318pp.

$\mathrm{Hu}$, Q.T., 2007. Study on the Mechanical Mechanism of Coal and Gas Outburst and its Application, China University of Mining \& Technology (Beijing), China, Beijing. 148 pp.

$\mathrm{Hu}$, Q.T. and Wen, G.C., 2013. Coal and Gas Outburst Mechanical Mechanism. Science Press, Beijing. pp 331-351. 
Jiang, C.L., 1994. Analyses on the developing process and mechanical conditions of coal gas outburst front. Journal of China University of Mining \& Technology 4, 1-9.

Jiang, C.L. and Yu, Q.X., 1996. Rules of energy dissipation in coal and gas outburst. Journal of China Coal Society 21(2), 173-178.

Kurnia, J.C., Sasmito, A.P. and Mujumdar, A.S., 2014. Dust dispersion and management in underground mining faces. International Journal of Mining Science and Technology 24(1), 39-44.

Lama, R.D. and Bodziony, J., 1998. Management of outburst in underground coal mines. International Journal of Coal Geology 35(1), 83-115.

Li, C.W., Xie, B.J., Cao, J.L., Wang, T.T. and Wang, X.Y., 2012. The energy evaluation model of coal and gas outburst intensity. Journal of China Coal Society 37(9), 1547-1552.

Li, W., Cheng Y.P., Wang, L. et al., 2013. Evaluating the security of geological coalbed sequestration of supercritical $\mathrm{CO} 2$ reservoirs: The Haishiwan coalfield, China as a natural analogue. International Journal of Greenhouse Gas Control 13(2), 102-111.

Li, W., Zhu, J.T., Cheng, Y.P. and Lu, S.Q., 2014. Evaluation of coal swelling-controlled CO 2 diffusion processes. Greenhouse Gases Science \& Technology, 4(1): 131-139.

Li, Y.B., Xue, S., Wang, J.F., Wang, Y.C. and Xie, J., 2014. Gas diffusion in a cylindrical coal sample - A general solution, approximation and error analyses. International Journal of Mining Science and Technology 24(1), 69-73.

Li, Y.B., Zheng, W.C. and Wang, F.S., 2013. The effect of coal sample particle size on coal adsorption constants and initial speed of methane diffusing. Safety in Coal Mines 1, 5-8.

Lin, J., 2004. Research on the flow property in the pneumatic conveying system, Zhejiang University, China, Hangzhou. 137 pp.

Litwiniszyn, J., 1985. A model for the initiation of coal-gas outbursts, International Journal of Rock Mechanics and Mining Sciences \& Geomechanics Abstracts. Elsevier, pp. 39-46.

Liu, Y.W., 2011. Study on Gas Emission Rules, Mechanism and dynamic model from coal particle, henan polytechnic university, Jiaozuo. $159 \mathrm{pp}$.

Liu, Y.W., Wei, J.P., He, Z.G. and Liu, M.J., 2013. Influence rules and mechanisms of temperature on dynamic process of gas diffusion from coal particles. Journal of China Coal Society 38(A01), 100-105.

Molerus, O., 1996. Overview: Pneumatic transport of solids. Powder Technology 88(3), 309-321.

Nandi, S.P. and Walker Jr, P.L., 1975. Activated diffusion of methane from coals at elevated pressures. Fuel 54(2), 81-86.

$\mathrm{Ni}$, G. et al., 2014. Kinetic characteristics of coal gas desorption based on the pulsating injection. International Journal of Mining Science and Technology 24(5), 631-636.

Pan, R., 1999. Material properties and flow modes in pneumatic conveying. Powder Technology 104(2), 157-163.

Paterson, L., 1986. A model for outbursts in coal, International Journal of Rock Mechanics and Mining Sciences \& Geomechanics Abstracts. Elsevier, pp. 327-332.

Ruckenstein, E., Vaidyanathan, A.S. and Youngquist, G.R., 1971. Sorption by solids with bidisperse pore structures. Chemical Engineering Science 26(9), 1305-1318.

Ruppel, T.C., Grein, C.T. and Bienstock, D., 1974. Adsorption of methane on dry coal at elevated pressure. Fuel 53(3), 152-162.

Smith, D.M. and Williams, F.L., 1984. Diffusion models for gas production from coal: determination 
of diffusion parameters. Fuel 63(2), 256-261.

Sobczyk, J., 2011. The influence of sorption processes on gas stresses leading to the coal and gas outburst in the laboratory conditions. Fuel, 90(3), 1018-1023.

$\mathrm{Su}$, X.B., 1990. The coal facies analysis of the main coal seams in the long tan formation of low permain from zhong liang shan and nan tong mining region, Sichuan. Journal of Jiao Zuo Mining Institute 3, 49-57.

Sun, W.Z. and Hu, D.S., 2012. Analysis of factors influencing coking coal's bulk density. Bao-Steel Technology 2, 10-14.

Tan, D.X., 2013. The disciplines of coal and gas outburst and the technology of comprehensive management in the conditions of extremely complex geology, China University of Mining \& Technology (Beijing), China, Beijing. 152 pp.

Toraño, J., Torno, S., Alvarez, E. and Riesgo, P., 2012. Application of outburst risk indices in the underground coal mines by sublevel caving. International Journal of Rock Mechanics and Mining Sciences 50, 94-101.

Valliappan, S. and Zhang, W., 1999. Role of gas energy during coal outbursts. International Journal for Numerical Methods in Engineering 44(7), 875 - 895.

Wang, S., Elsworth, D. and Liu, J., 2015. Rapid decompression and desorption induced energetic failure in coal. Journal of Rock Mechanics and Geotechnical Engineering. In press. http://dx.doi.org/10.1016/j.jrmge.2015.01.004

Watanabe, E., 1985. The initial gas desorption rate as an index of burst of coal and gas: about the parameter of Kt. Safety in Coal Mines 5, 56-63.

Wen, G.C., Zhou, J. and Liu, S., 2002. Study in intrinsic gas energy to do work in outbursts. Mining Safety \& Environmental Protection 29(1), 1-3.

Williams, R.J. and Weissmann, J.J., 1995. Gas emission and outburst assessment in mixed CO2 and CH4 environments. Proc. ACIRL Underground Mining Sem. Australian Coal Industry Res. Lab., North Ryde, 12: 20.

Xiong, Y.J. et al., 2009. Blockage critical state of pulverized coal dense-phase pneumatic conveying in horizontal pipe. Chemical Journal 6, 1421-1426.

Xu, T., Tang, C.A., Yang, T.H., Zhu, W.C. and Liu, J., 2006. Numerical investigation of coal and gas outbursts in underground collieries. International Journal of Rock Mechanics and Mining Sciences 43(6), 905-919.

Yang, Q.L., 1987. Research on the gas desorption characteristics of coal particles. Safety in Coal Mines 2, 9-16.

Yu, B.F., 1978. Coal and Gas Outburst Mechanism. China Coal Industry Publishing House, Beijing. $282 \mathrm{pp}$.

Zhang, T.J., Xu, H.J., Li, S.G. and Ren, S.X., 2009. The effect of particle size on adsorption of methane on coal. Journal of Hunan University of Science \& Technology (Natural Science Edition) 1, 9-12.

Zhang, X.D., Sang, S.X., Qin, Y., Zhang, J. and Tang, J.X., 2005. Isotherm adsorption of coal samples with different grain size. Journal of China University of Mining \& Technology 34(4), 427-432.

Zhao, W., Cheng, Y., Yuan, M. and An, F., 2014. Effect of adsorption contact time on coking coal particle desorption characteristics. Energy \& Fuels 28(4), 2287-2296.

Zheng, Z., 2004. The mechanism of coal and gas outburst from the view of quantity and dimensional 
analysis. Collected Works of Zhe-Min Zheng. Science Press, Beijing. pp. 382-392.

1 Zhou, S.N., 1990. Mechanism of gas flow in coal seams. Journal of China Coal Society 1, 15-24. 


\section{Figures in color}
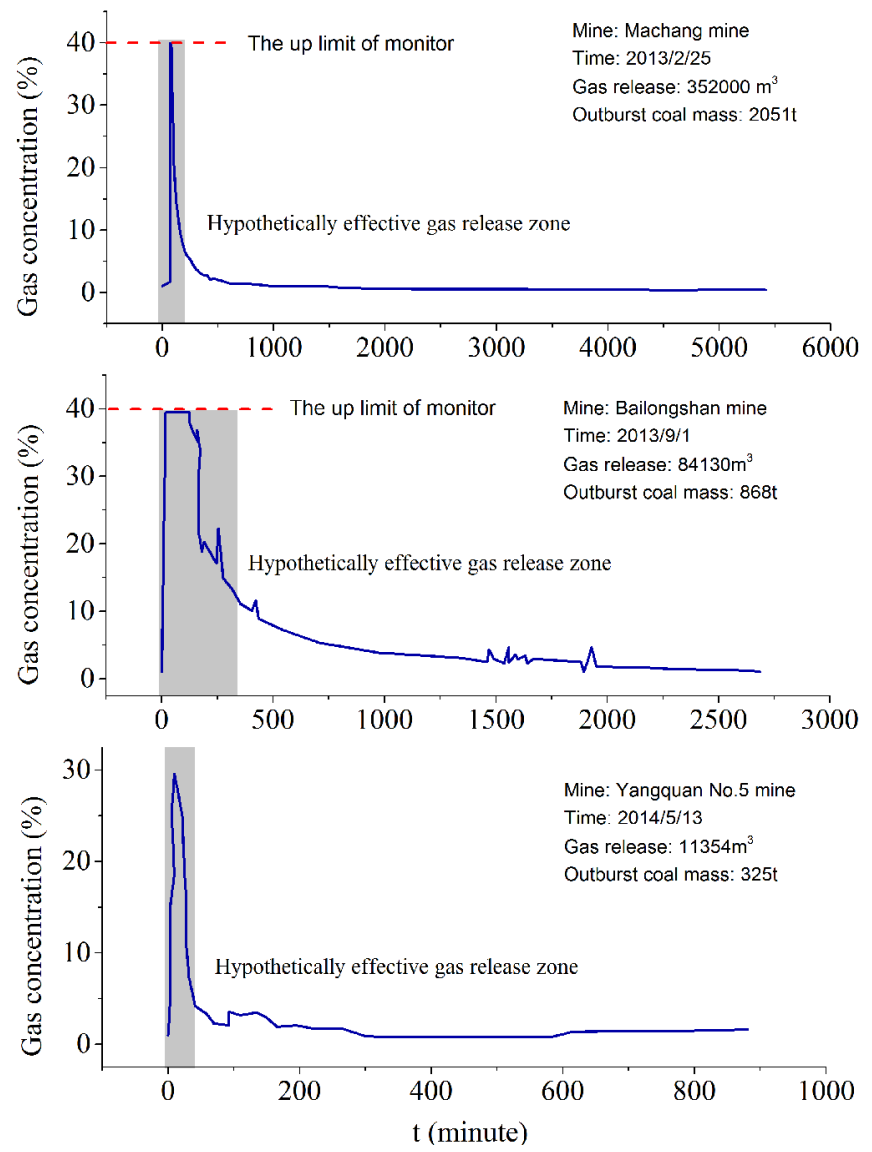

Figure 1 Variation in roadway gas concentration over time for three recent outbursts 


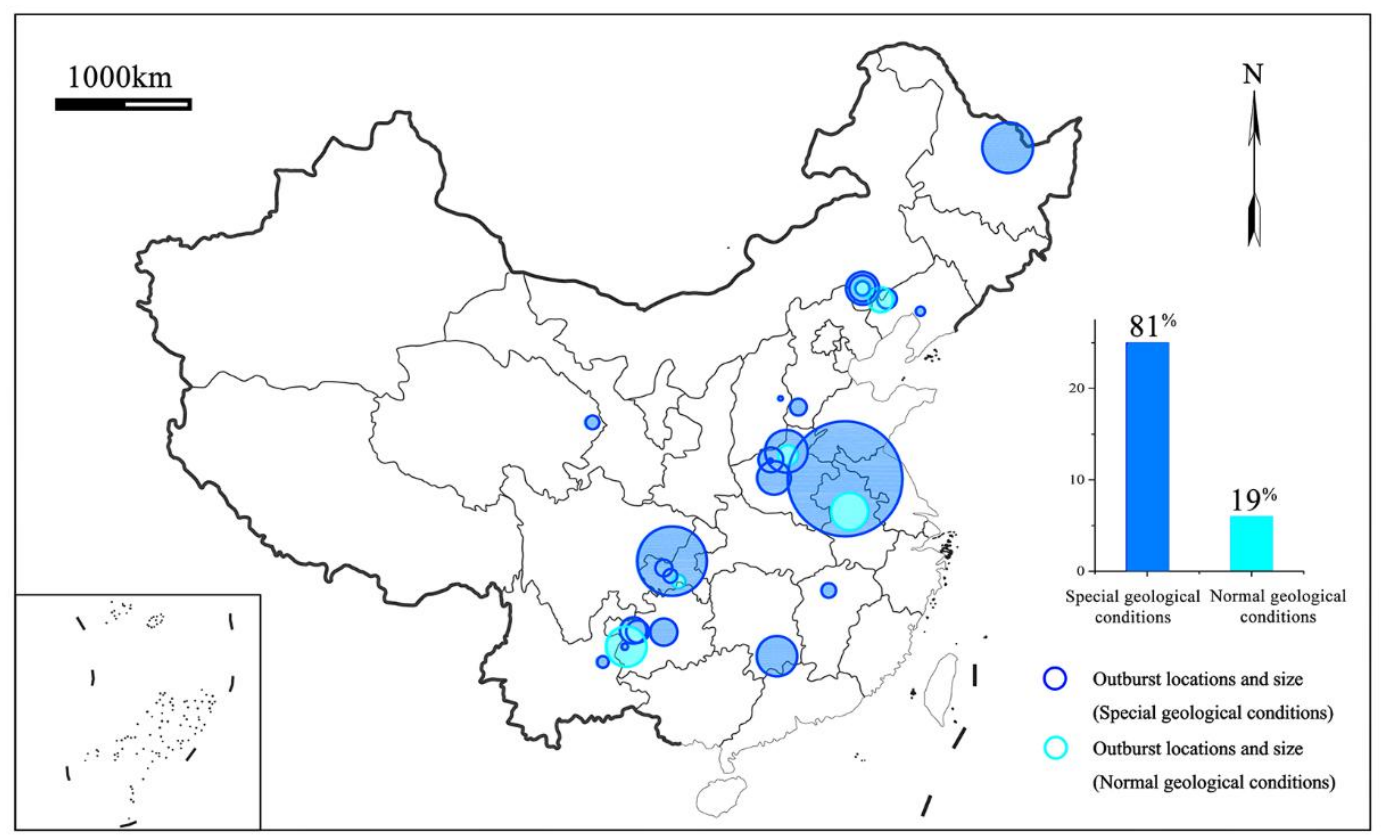

Figure 2 Location and size of outbursts with special or normal geological conditions in China 


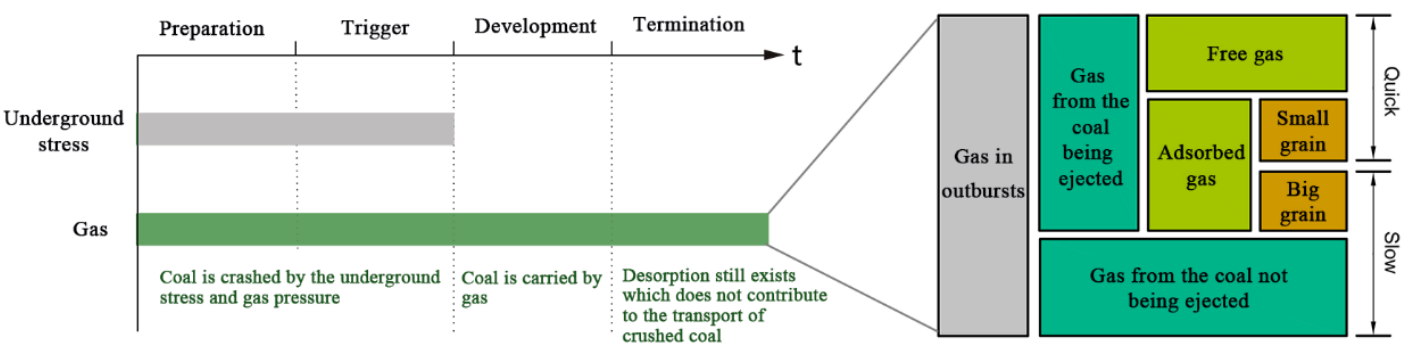

Figure 3 Role of gas and underground stress during the different stages of an outburst 


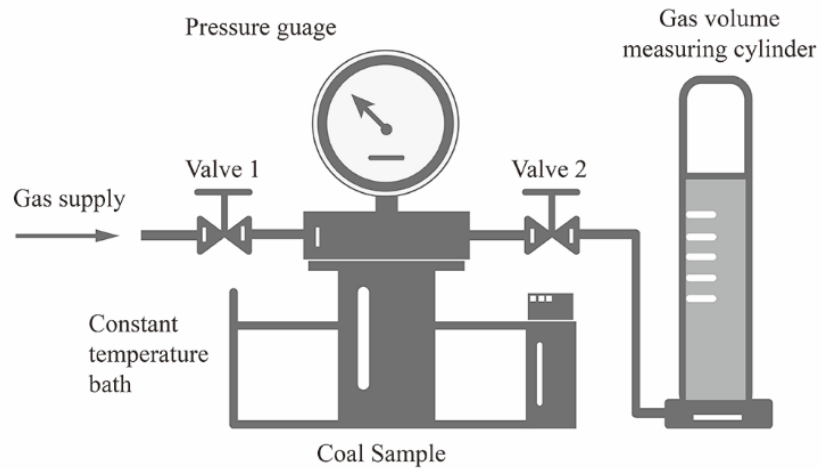

Figure 4 Test equipment 


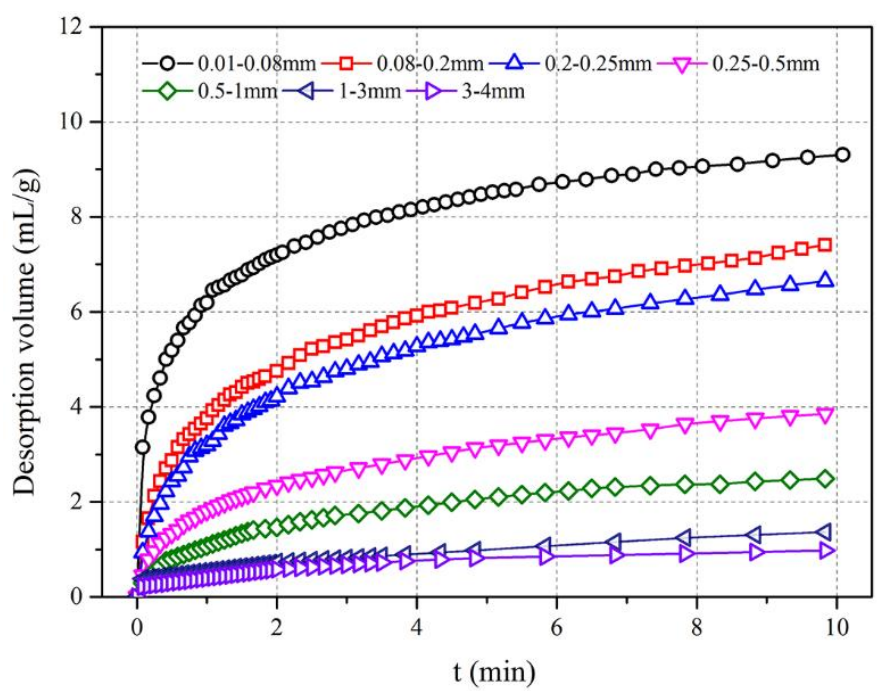

Figure 5 Changes in desorption volume over time 


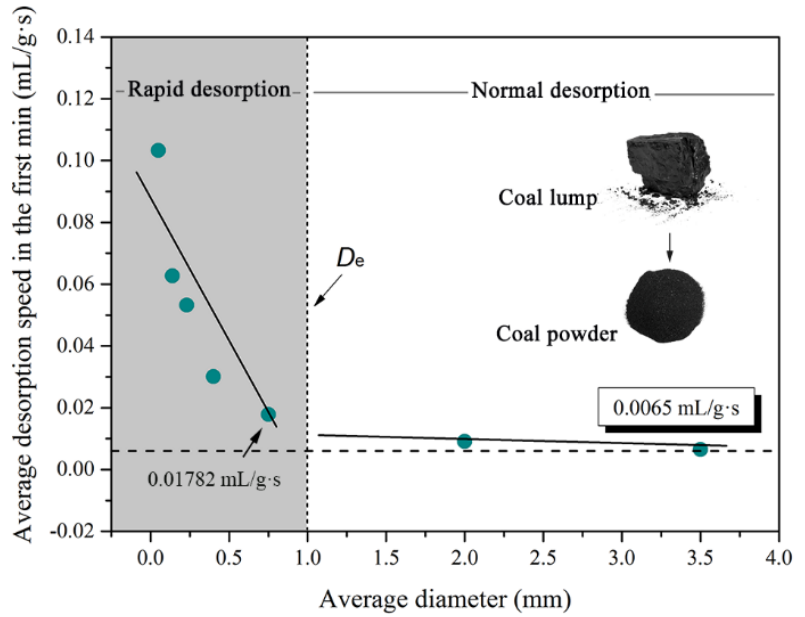

Figure 6 Relationship between the average desorption speed in the first minute and the average diameter 


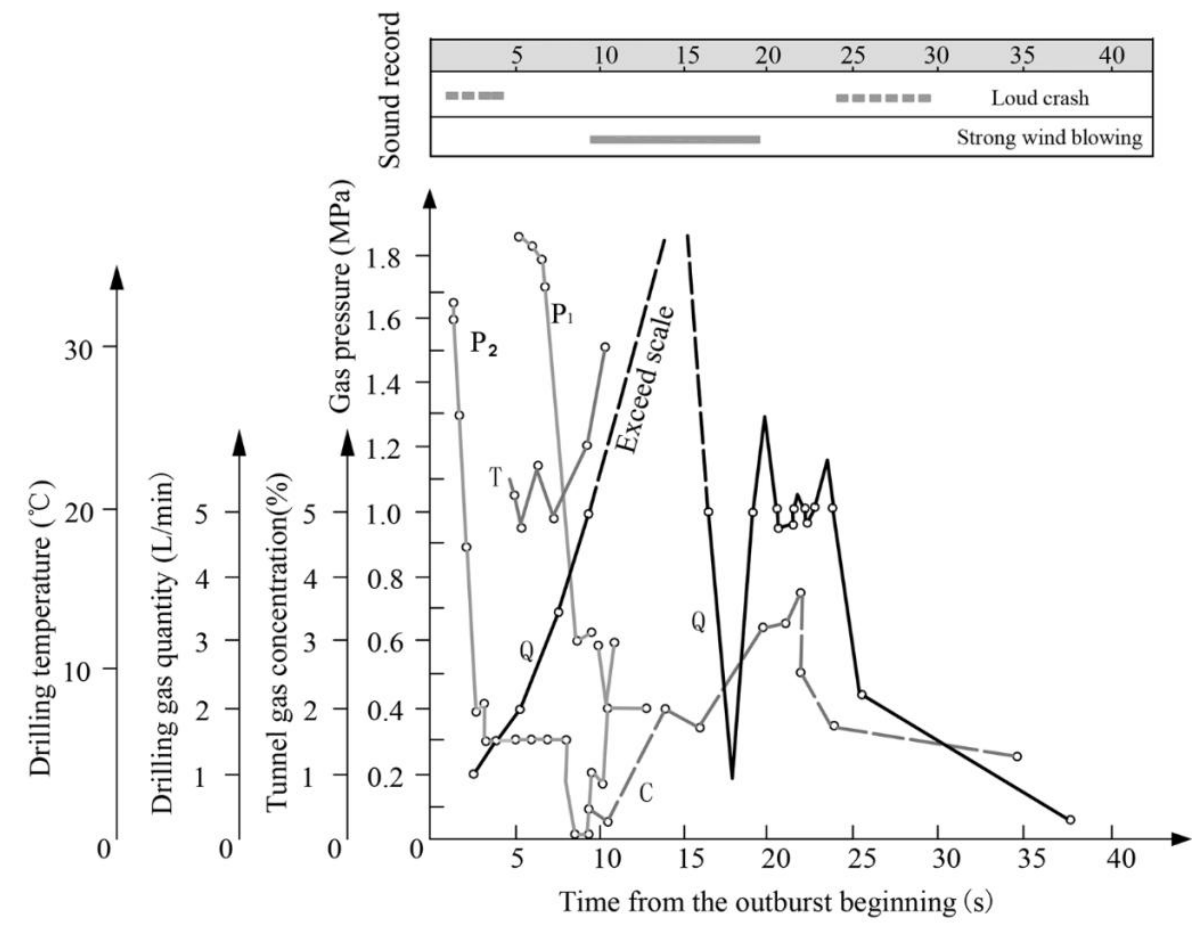

Figure 7 Parameter variations during the Zhongliangshan outburst (Hu and Wen, 2013) 


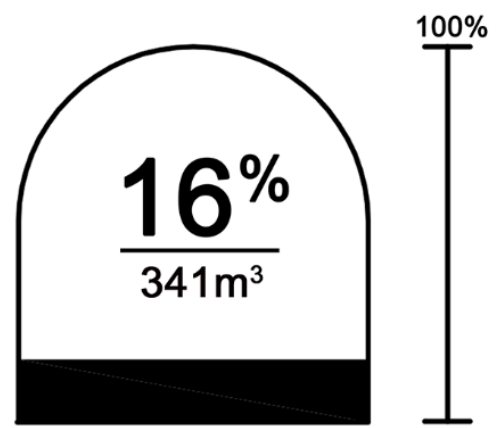

Free gas energy contribution

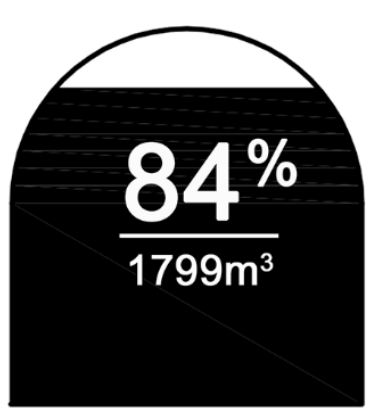

Adsorbed gas energy contribution

Figure 8 Energy contributions of free and adsorbed gas to the outburst 


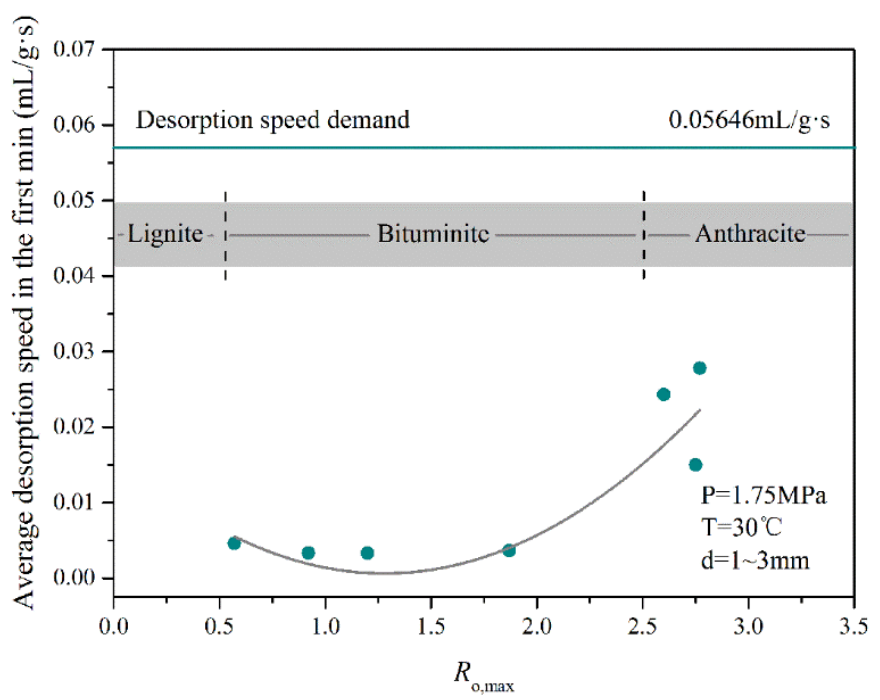

Figure 9 Variations in gas desorption speed of normal-sized particles with coal rank under a pressure of $1.75 \mathrm{MPa}$ 


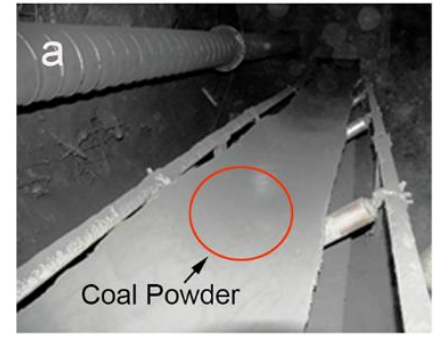

a. Coal powder on the belt conveyor

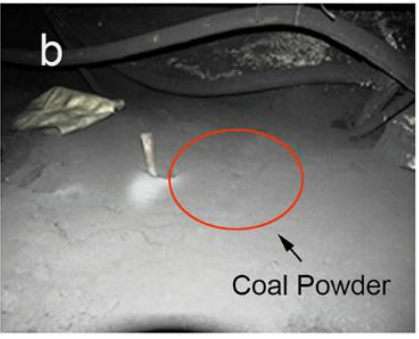

b. Coal powder in the tunnel

Figure 10 Coal powders in the Machang outburst 

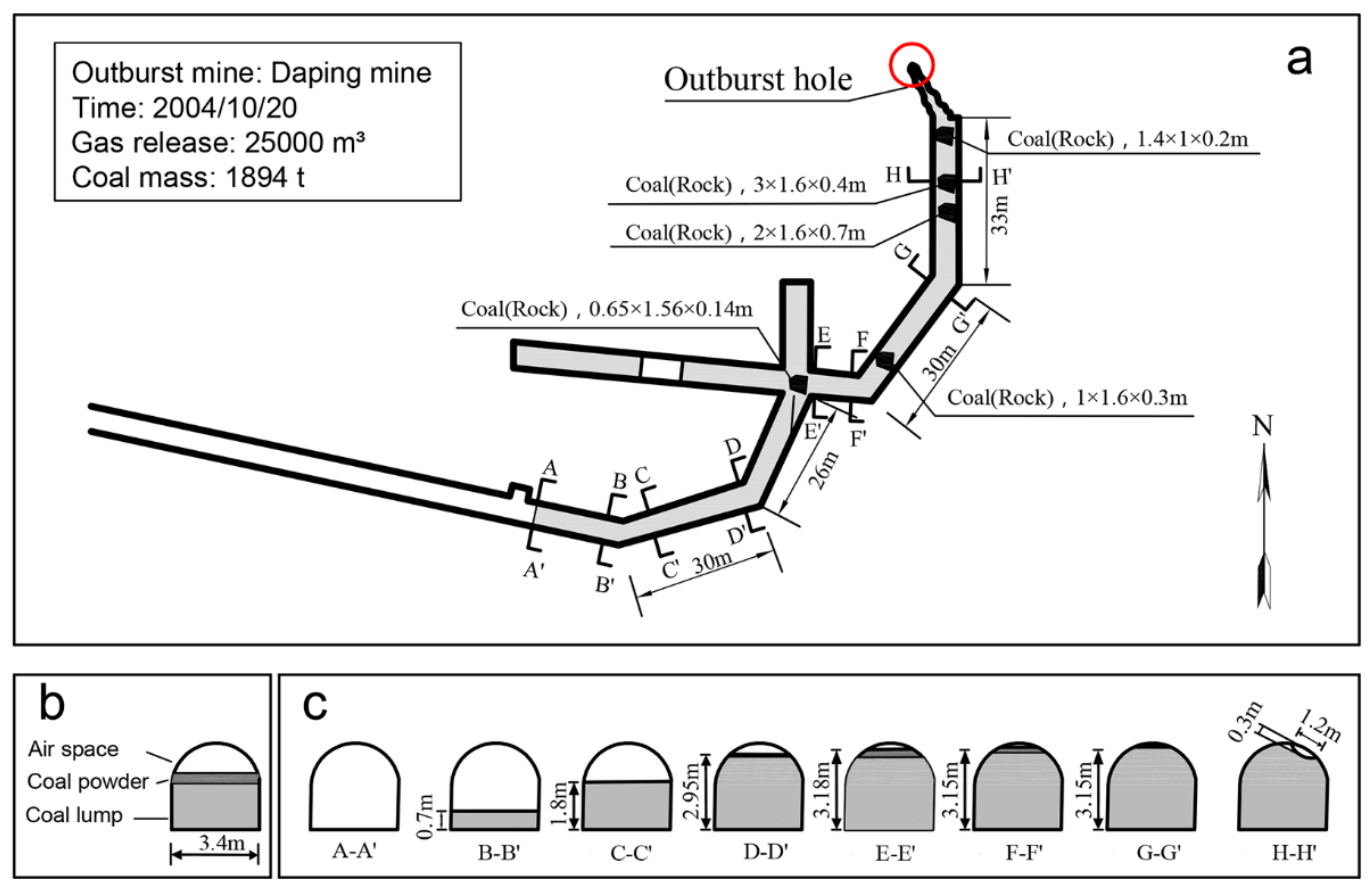

Figure 11 Sketch map of coal powder distribution along the roadway of the Daping outburst a. Planar graph of coal powder distribution in roadways. b. Zone classifications of the coal deposits. c. Height variation of the coal deposit along the roadway and the composition of the coal. 


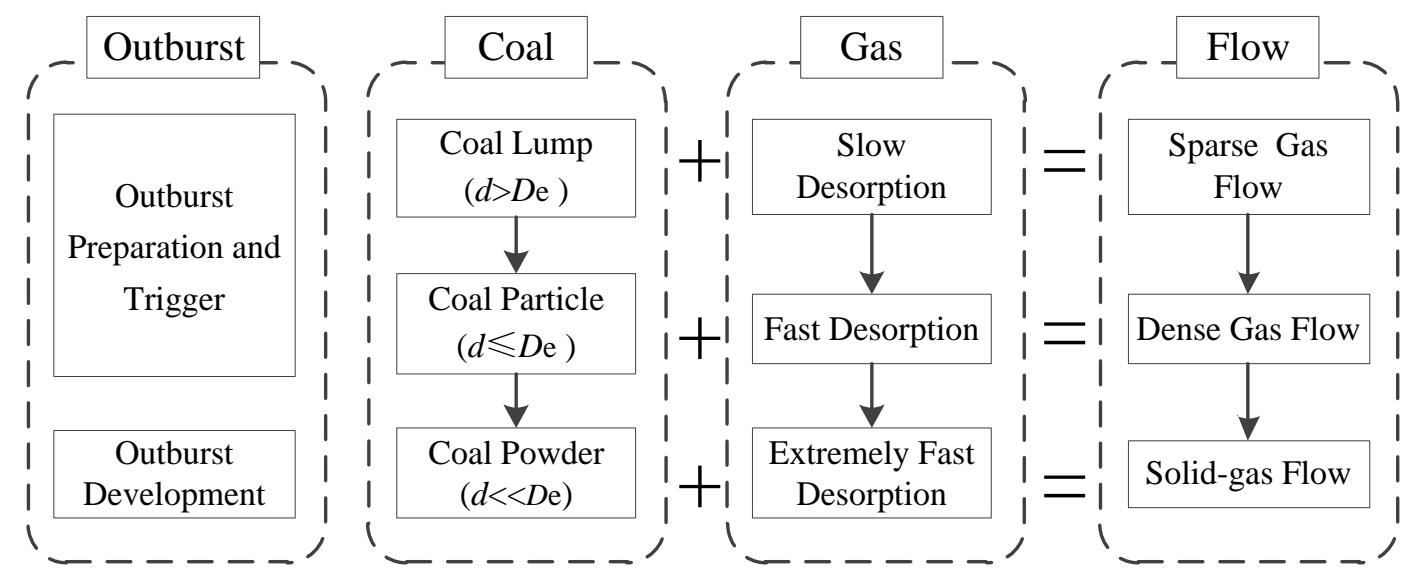

Figure 12 Role of coal powders in outbursts 


\section{Figures in black and white}
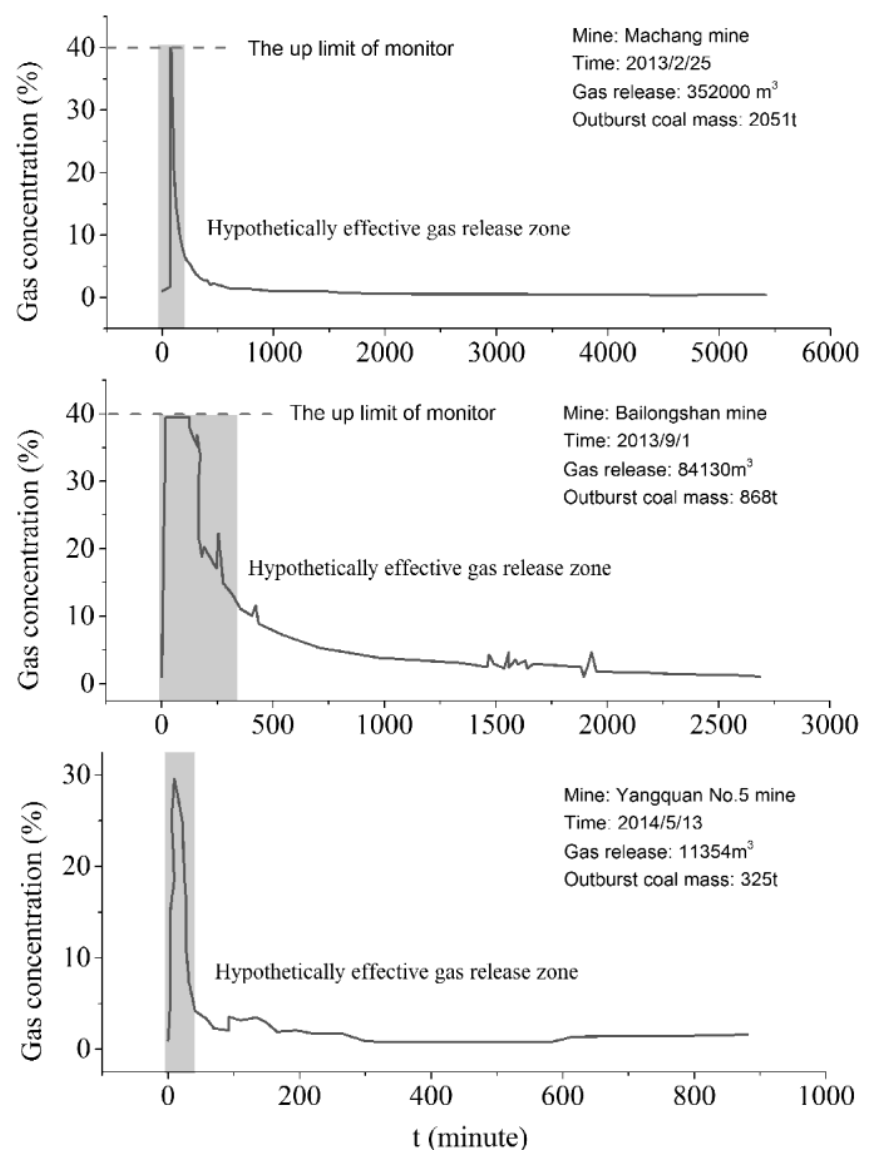

Figure 1 Roadway gas concentration change over time in three recent outbursts 


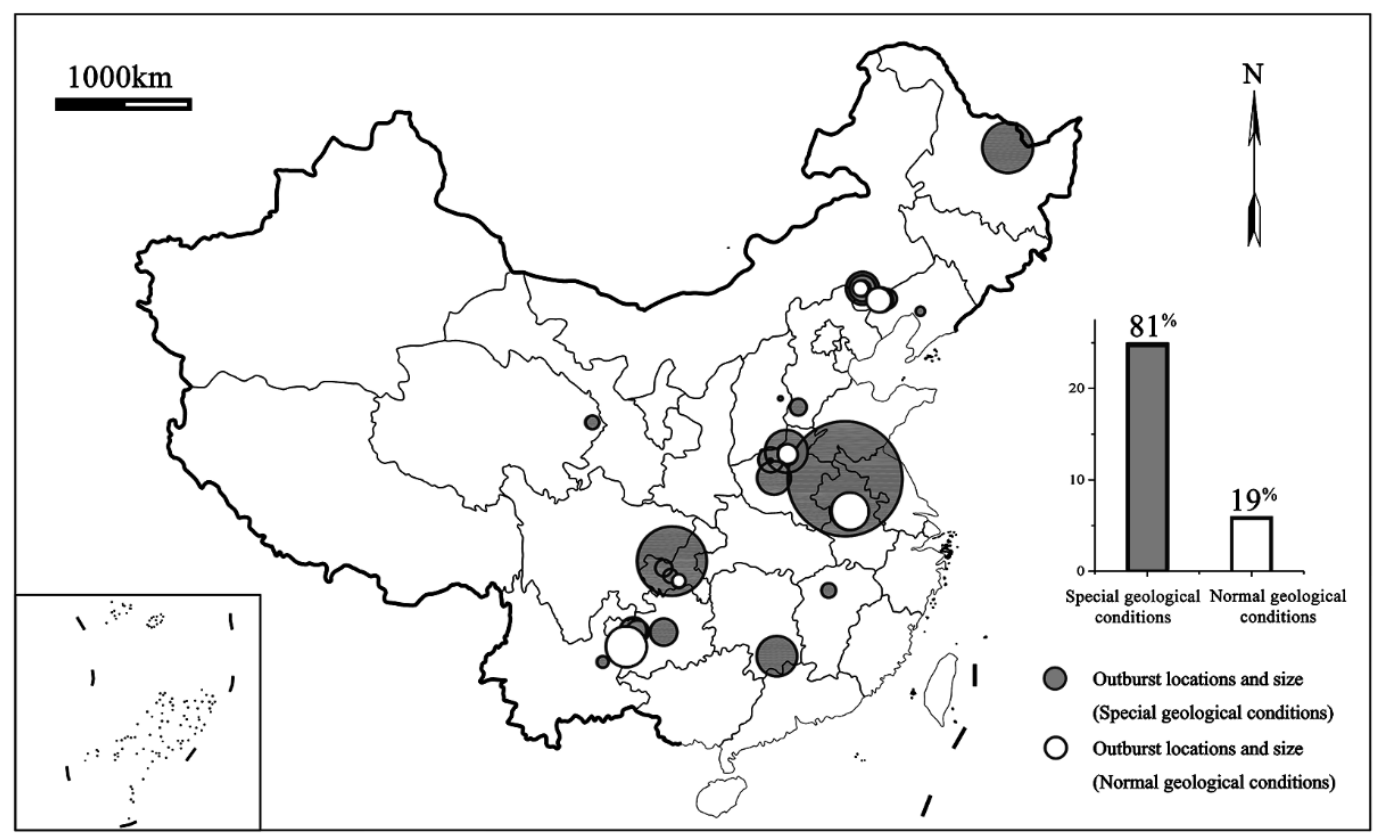

Figure 2 Location and size of outbursts with special or normal geological conditions in China 


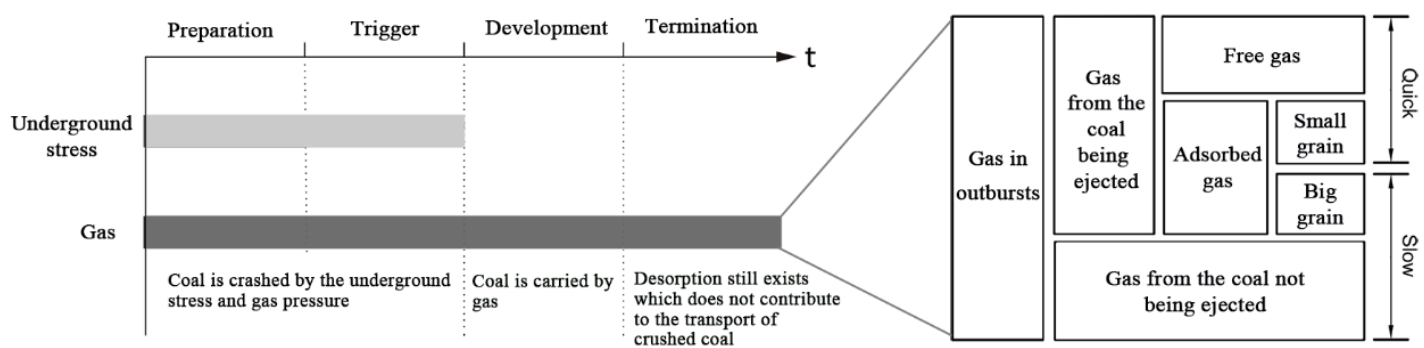

Figure 3 Role of gas and underground stress in the different stages of an outburst 


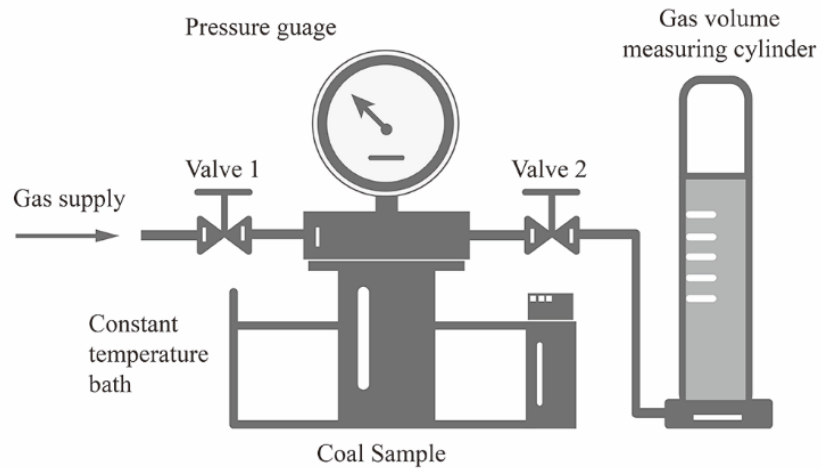

Figure 4 Test equipment 


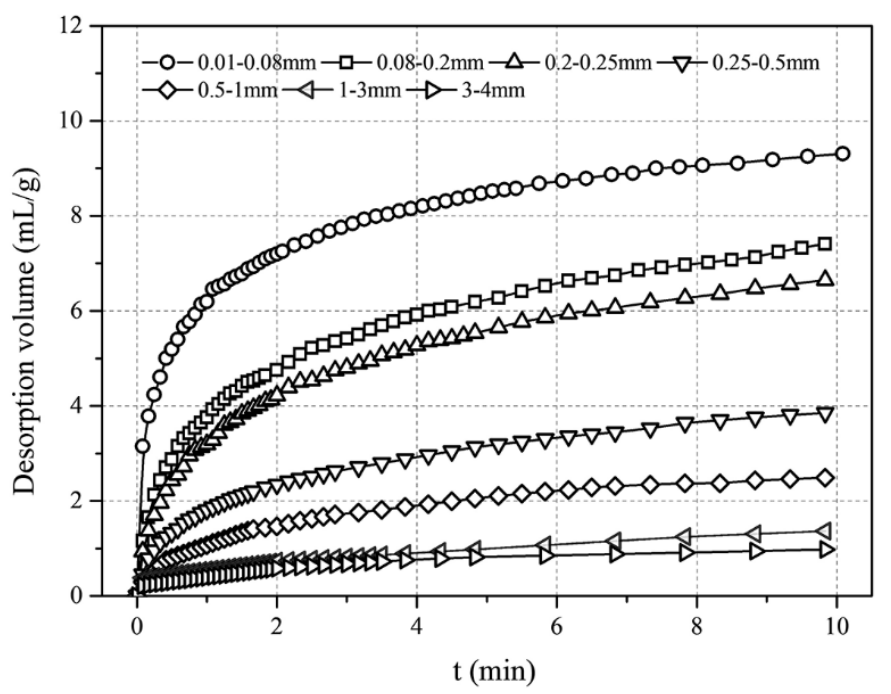

Figure 5 Desorption volume changes over time 


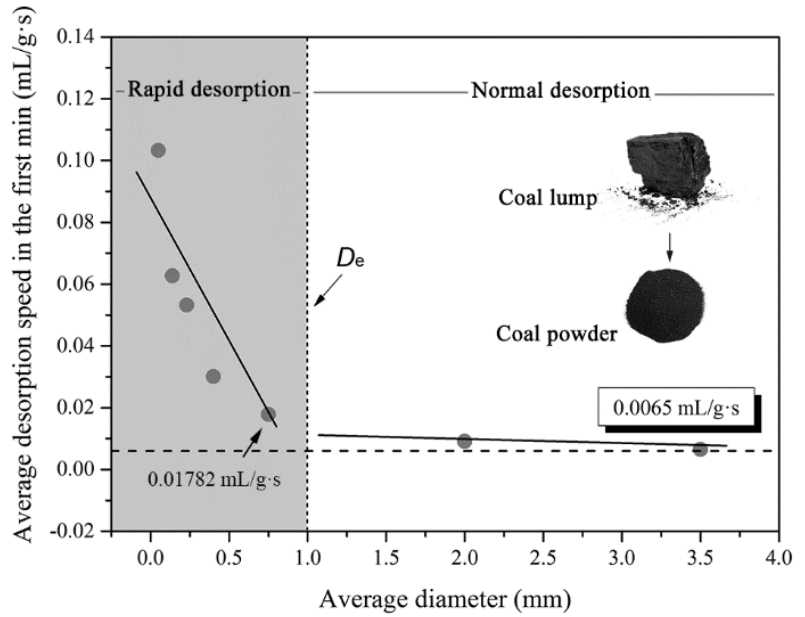

Figure 6 Relationship between the average desorption speed in the first minute and the average diameter 


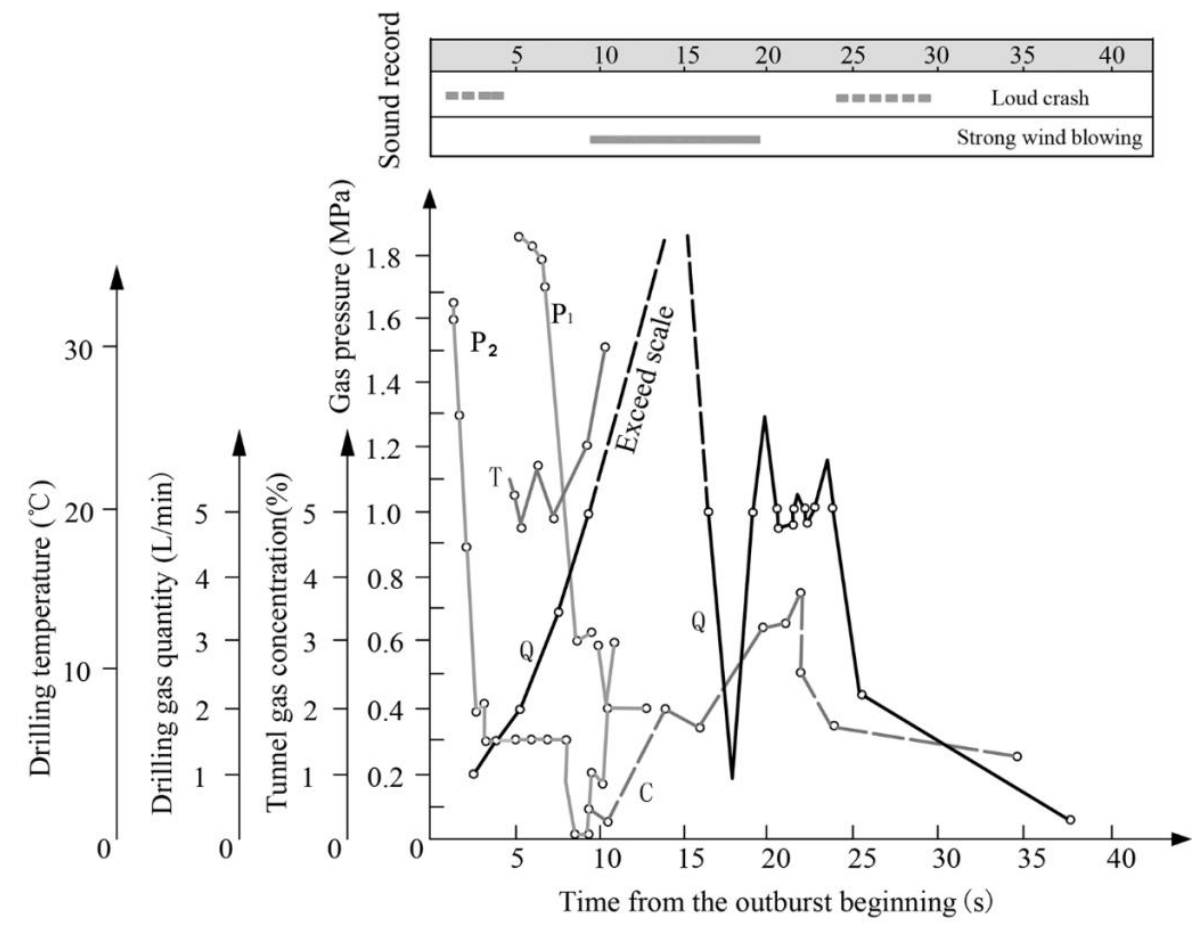

Figure 7 Parameter variations during the Zhongliangshan outburst (Hu and Wen, 2013) 


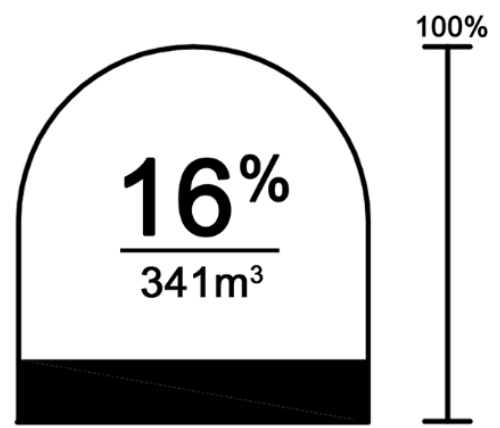

Free gas energy contribution

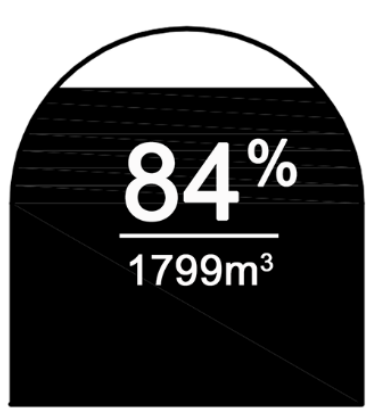

Adsorbed gas energy contribution

Figure 8 Energy contributions of free and adsorbed gas to the outburst 


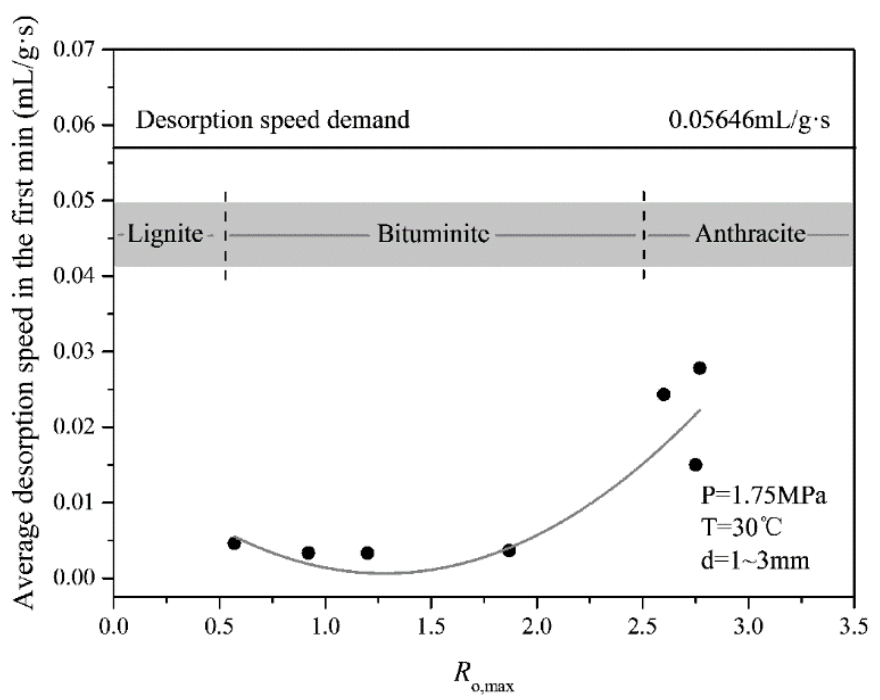

Figure 9 Variations in gas desorption speed of normal-sized particles with coal rank under a pressure of $1.75 \mathrm{MPa}$ 


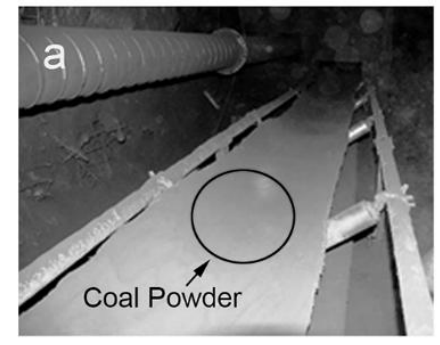

a. Coal powder on the belt conveyor

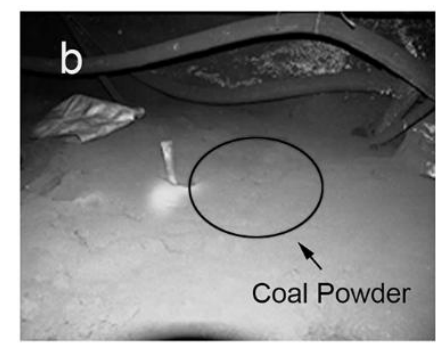

b. Coal powder in the tunnel

Figure 10 Coal powders in the Machang outburst 

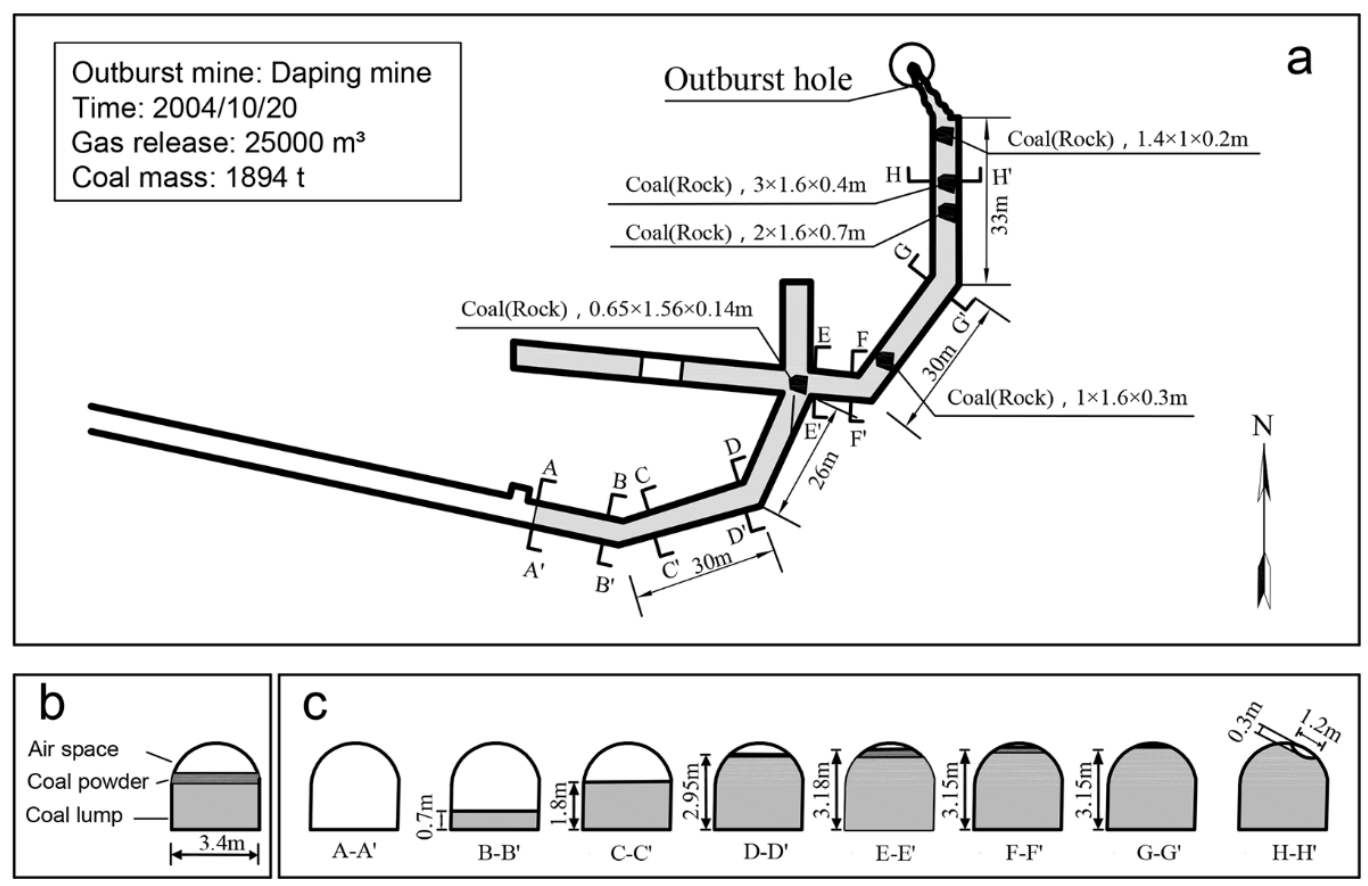

Figure 11 Sketch map of coal powder distribution along the roadway of the Daping outburst a. Planar graph of coal powder distribution in roadways. b. Zone classifications of the coal deposits. c. Height variation of the coal deposit along the roadway and its composition. 


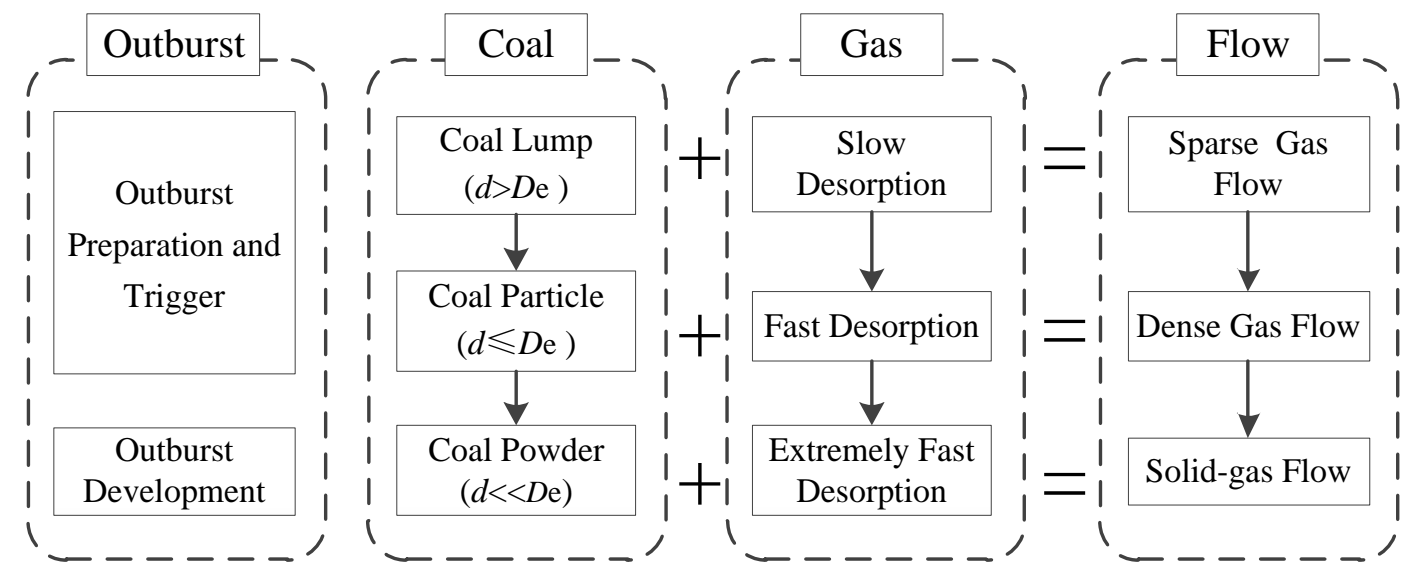

Figure 12 Role of coal powders in outbursts 


\section{Tables}

Table 1 Statistics of outbursts in China

\begin{tabular}{|c|c|c|c|c|c|}
\hline No. & Mine & Date & Size/t & Gas released $/ \mathrm{m}^{3}$ & Geological structure \\
\hline 1 & Songzao & $1960 / 05 / 14$ & 1,000 & 128,000 & Normal \\
\hline 2 & Dayong & $1967 / 01 / 12$ & 2,000 & $1,300,000$ & Broken coal in roof \\
\hline 3 & Sanbao & $1967 / 03 / 13$ & 1,500 & 100,000 & Unnormal coal occurence \\
\hline 4 & Hongwei & $1967 / 07 / 08$ & 2,000 & 960,000 & Unnormal coal occurence \\
\hline 5 & Moxinpo & $1970 / 03 / 10$ & 5,270 & - & Heavily structured \\
\hline 6 & Yinggangling & 1970/06/06 & 1,100 & - & Unnormal coal occurence \\
\hline 7 & Mugang & $1971 / 03 / 26$ & 1,700 & 180,000 & Heavily structured \\
\hline 8 & Sanbao & $1973 / 05 / 29$ & 1,500 & 54,400 & Fold \\
\hline 9 & Hongwei & $1973 / 10 / 29$ & 2,500 & 500,000 & Fold \\
\hline 10 & Hongwei & $1975 / 07 / 18$ & 1,100 & 284,000 & Heavily structured \\
\hline 11 & Yanmazhuang & $1975 / 08 / 04$ & 1,500 & 440,000 & Normal \\
\hline 12 & Sanhui & 1975/08/08 & 1,278 & $1,400,000$ & Fault \\
\hline 13 & Guanshan & 1977/12/08 & 1,894 & 164,000 & Normal \\
\hline 14 & Yaojie & $1978 / 05 / 24$ & 1,030 & 240,000 & Heavily structured \\
\hline 15 & Hongwei & $1979 / 02 / 19$ & 1,200 & 230,000 & Normal \\
\hline 16 & Zhonliangshan & $1979 / 02 / 20$ & 1,050 & 26,000 & Heavily structured \\
\hline 17 & Sanwu & $1979 / 03 / 21$ & 3,060 & $1,380,000$ & Heavily structured \\
\hline 18 & Luling & $2002 / 04 / 07$ & 8,729 & 930,000 & Fault \\
\hline 19 & Hongling & $2004 / 08 / 14$ & 701 & 66,266 & Heavily structured \\
\hline 20 & Daping & $2004 / 10 / 20$ & 1,894 & 249,501 & Fault \\
\hline 21 & Wangfenggang & $2006 / 01 / 05$ & 2,831 & 292,700 & Normal \\
\hline 22 & Malingshan & $2006 / 01 / 20$ & 339 & 28,341 & Heavily structured \\
\hline 23 & Dashucun & $2007 / 04 / 29$ & 1,270 & 93,000 & Fault \\
\hline 24 & Xinxing & $2009 / 11 / 21$ & 3,845 & 166,300 & Fault \\
\hline 25 & Pingyu & 2010/10/16 & 2,547 & 150,000 & Heavily structured \\
\hline 26 & Jiulishan & 2011/10/27 & 3,246 & 291,000 & Heavily structured \\
\hline 27 & Xiangshui & $2012 / 11 / 24$ & 490 & 45,000 & Fault \\
\hline 28 & Jinjia & 2013/01/18 & 3,060 & $1,380,000$ & Normal \\
\hline 29 & Machang & 2013/03/12 & 2,051 & 352,000 & Fault and folds \\
\hline 30 & Bailongshan & 2013/09/01 & 868 & 84,130 & Fault \\
\hline 31 & Yangmei No.5 mine & $2014 / 05 / 14$ & 325 & 11,354 & Heavily structured \\
\hline
\end{tabular}

Note: The data was provided by the State Administration of Work Safety, China. 
Table 2 Calculation parameters (An et al., 2013; Hu and Wen, 2013; Su, 1990; Sun and Hu, 2012; Wen et al., 2002).

\begin{tabular}{llll}
\hline Outburst coal mass $/ \mathrm{t}$ & 817 & Outburst coal rank & Coking coal \\
Gas released $/ \mathrm{m}^{3}$ & 38540 & Porosity $/ \%$ & 6 \\
Outburst period/t & 39 & Roadway cross-section area $/ \mathrm{m}^{3}$ & 7 \\
Outburst distance $/ \mathrm{m}$ & 167 & Initial Pressure $/ \mathrm{MPa}$ & 1.75 \\
Coal bulk density $/ \mathrm{kg} \cdot \mathrm{m}^{-3}$ & 700 & Methane density $\left(30^{\circ} \mathrm{C}, 0.1 \mathrm{MPa}\right) / \mathrm{kg} \cdot \mathrm{m}^{-3}$ & 0.6375 \\
Coal apparent density $/ \mathrm{kg} \cdot \mathrm{m}^{-3}$ & 1300 & Friction coefficient & 0.5 \\
Adiabatic coefficient $/ \mathrm{n}$ & 1.3 & & \\
\hline
\end{tabular}

Note: The initial outburst pressure is the average value of hole \#1 and \#2. 
Table 3 Results detailing the different energies involved in the Zhongliangshan outburst

\begin{tabular}{|c|c|c|c|c|c|c|c|c|}
\hline \multirow[b]{2}{*}{$\begin{array}{c}\text { Coal } \\
\text { transport } \\
\text { energy } \\
\text { /J }\end{array}$} & \multicolumn{3}{|c|}{ Free gas expansion energy } & \multicolumn{3}{|c|}{ Gas remained kinetic energy } & \multicolumn{2}{|c|}{$\begin{array}{c}\text { Supply desorption } \\
\text { gas }\end{array}$} \\
\hline & $\begin{array}{c}\text { Free } \\
\text { gas } \\
\text { volume } \\
/ \mathrm{m}^{3}\end{array}$ & $\begin{array}{c}\text { Gas } \\
\text { expansion } \\
\text { energy } \\
\text { /J }\end{array}$ & $\begin{array}{c}\text { Gas } \\
\text { expansion } \\
\text { energy } \\
\text { factor } \\
\lambda_{1} \\
\end{array}$ & $\begin{array}{c}\text { Blockage } \\
\text { critical } \\
\text { velocity } \\
/ \mathrm{m} \cdot \mathrm{s}^{-1}\end{array}$ & $\begin{array}{c}\text { Remained } \\
\text { kinetic } \\
\text { energy } \\
\text { /J }\end{array}$ & $\begin{array}{c}\text { Remained } \\
\text { kinetic } \\
\text { energy } \\
\text { factor } \\
\lambda_{2}\end{array}$ & $\begin{array}{c}\text { Energy } \\
\text { /J }\end{array}$ & $\begin{array}{c}\text { Gas } \\
\text { volume } \\
/ \mathrm{m}^{3}\end{array}$ \\
\hline $6.67 \times 10^{8}$ & 341 & $1.06 \times 10^{8}$ & $3.12 \times 10^{5}$ & 4.28 & 1986 & 5.83 & $5.61 \times 10^{8}$ & 1799 \\
\hline
\end{tabular}


Table 4 1 3 mm coal particle desorption speed of the first minute from different sections

\begin{tabular}{|c|c|c|c|c|c|}
\hline Section & $\begin{array}{l}\text { Chinese coal } \\
\text { classification }\end{array}$ & $R_{\mathrm{o}, \max }$ & $\begin{array}{l}\text { Relation between the } \\
\text { first minute desorption } \\
\text { and the initial pressure }\end{array}$ & $\begin{array}{l}\text { The first minute } \\
\text { desorption speed } \\
\text { under } 1.75 \mathrm{MPa} \\
\quad / \mathrm{mL} / \mathrm{g} \cdot \mathrm{s}\end{array}$ & $\begin{array}{l}\text { Ideal TCPS } \\
\text { /um } \\
\text { (Equation 22) }\end{array}$ \\
\hline Dalong & Long flame & 0.57 & $Q_{1}=0.1719 P^{0.8403}$ & 0.004584 & 351 \\
\hline Renlou & Gas-fat & 0.92 & $Q_{1}=0.1360 P^{0.6900}$ & 0.003333 & 21 \\
\hline Shuangliu & Coking & 1.20 & $Q_{1}=0.16108 P^{0.3734}$ & 0.003309 & 20 \\
\hline Tunlan & Coking & 1.87 & $Q_{1}=0.14739 P^{0.6910}$ & 0.003616 & 24 \\
\hline $\begin{array}{l}\text { Jinhuang } \\
\text { zhuang }\end{array}$ & 1/3 Coking & - & $Q_{1}=0.2157 P^{0.5436}$ & 0.004873 & 39 \\
\hline Bailongshan & Anthracite & 2.60 & $Q_{1}=1.0935 P^{0.5151}$ & 0.02431 & 515 \\
\hline Daning & Anthracite & 2.77 & $Q_{1}=1.0491 P^{0.8294}$ & 0.02781 & 640 \\
\hline Wolonghu & Anthracite & 2.75 & $Q_{1}=0.6734 P^{0.5173}$ & 0.01499 & 236 \\
\hline
\end{tabular}


Table 5 Coal size distribution of Zhongliangshan's four outbursts that occurred in the 1970s and 1980s (Hu, 2007)

\begin{tabular}{|c|c|c|c|c|c|c|}
\hline \multirow{2}{*}{ No. } & \multicolumn{5}{|c|}{ Diameter/mm } & \multirow{2}{*}{ Outburst location } \\
\hline & $<0.1$ & $0.1 \sim 1.0$ & $1 \sim 5$ & $5 \sim 10$ & $>10$ & \\
\hline 1 & $25.4 \%$ & $26.0 \%$ & $27.6 \%$ & $1.0 \%$ & $20.0 \%$ & $\begin{array}{c}\mathrm{K}_{2} \text { coal seam at the open-off cut of the } 5 \text { th } \\
\text { cross-cut, }+280 \text { m elevation }\end{array}$ \\
\hline 2 & $4.3 \%$ & $29.9 \%$ & $24.6 \%$ & $14.1 \%$ & $27.2 \%$ & $\begin{array}{l}\mathrm{K}_{1} \text { coal seam at the Xisi half rising cross-cut, } \\
\qquad+280 \text { m elevation }\end{array}$ \\
\hline 3 & $3.5 \%$ & $30.4 \%$ & $30.5 \%$ & $19.4 \%$ & $16.2 \%$ & $\begin{array}{l}\mathrm{K}_{10} \text { coal seam at the } 5 \text { th cross-cut, }+280 \mathrm{~m} \\
\text { elevation (The same coalseam with that of the } \\
\text { studied outburst) }\end{array}$ \\
\hline 4 & $6.6 \%$ & $27.5 \%$ & $16.9 \%$ & $18.2 \%$ & $30.8 \%$ & $\begin{array}{l}\mathrm{K}_{10} \text { coal seam at the Xisi half rising cross-cut, } \\
+280 \text { m elevation (The same coalseam with } \\
\text { that of the studied outburst) }\end{array}$ \\
\hline
\end{tabular}

